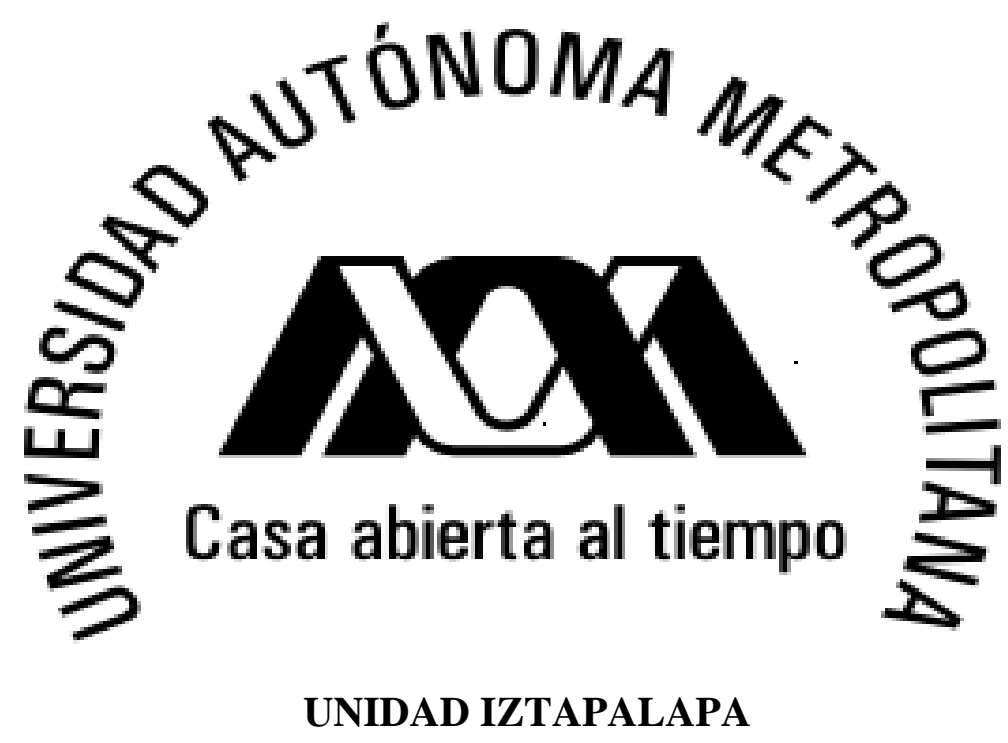

DIVISIÓN: CIENCIAS SOCIALES Y HUMANIDADES

\title{
INDETERMINACIÓN DE LA REFERENCIA Y RELATIVIDAD ONTOLÓGICA
}

\author{
I.C.R.
}

Para obtener el grado de Maestría en Humanidades

Por:

Rogelio Miranda Vilchis

Asesor: Dr. Silvio José Mota Pinto

México DF, Julio 2014 
INDETERMINACION DE LA

REFERENCIA Y RELATIVIDAD

ONTOLOGICA

En México, D.F., se presentaron a las 13.00 horas del día 10 del mes de octubre del año 2014 en la Unidad Iztapalapa de la Universidad Autónoma Metropolitana, los suscritos miembros del jurado

DR. JOSE JORGE MAX FERNANDEZ DE CASTRO TAPIA

DR. SILVIO JOSE MOTA PINTO

DR. JORGE ROLANDO TAGLE MARROQUIN

Bajo la Presidencia del primero y con carácter de Secretario el último, se reunieron para proceder al Examen de Grado cuya denominación aparece al margen, para la obtención del grado de:

MAESTRO EN HUMANIDADES (FILOSOFIA)

DE: ROGELIO MIRANDA VILCHIS

y de acuerdo con el artículo 78 fracción III del Reglamento de Estudios Superiores de la Universidad Autónoma Metropolitana, los miembros del jurado resolvieron:

\section{APROBAR}

Acto continuo, el presidente del jurado comunicó al interesado el resultado de la evaluación y, en caso

aprobatorio, le fue tomada la protesta.

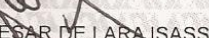
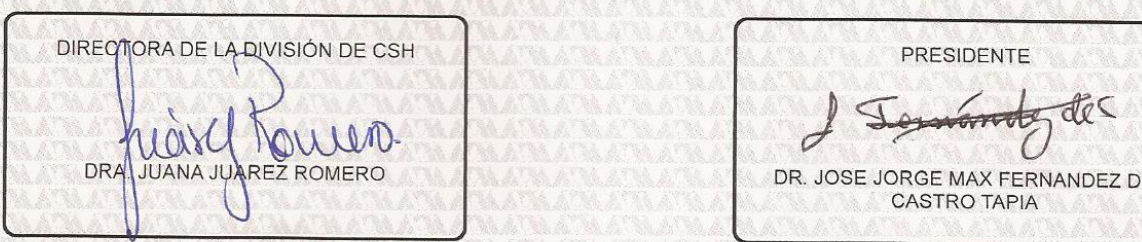

DR. JOSE JORGE MAX FERNANDEZ DE CASTRO TAPIA
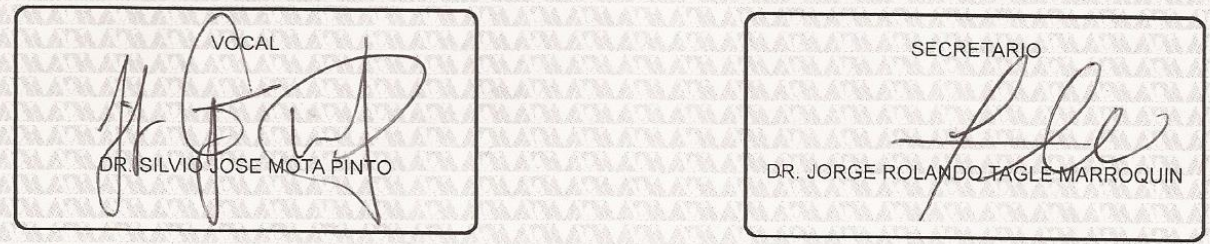
A mis padres

Rogelio e Ignacia 


\section{AGRADECIMIENTOS}

Gracias a mis padres Ignacia Vilchis Sánchez y Rogelio Miranda Martínez por su cariño y apoyo incondicional.

Infinitas gracias al Dr. Silvio José Mota Pinto por el apoyo, la paciencia y el tiempo invertidos en la supervisión de este trabajo, sin los cuales no hubiera sido posible la realización del mismo.

Por sus enseñanzas, gracias a los profesores: Yolanda Torres, Armando Cíntora, Álvaro Pelaéz, Enrique Serrano, Jorge Ornelas y Violeta Aréchiga.

A CONACYT por el apoyo económico para realizar los estudios de maestría

No puedo olvidar agradecer a mis compañeros Alberto Morales, Manuel Márquez, Marc Jiménez, Leónides García, Lourdes Argonza y Gerardo Allende por su amistad. 


\section{ÍNDICE}

AGRADECIMIENTOS ............................................................................................................................... 6

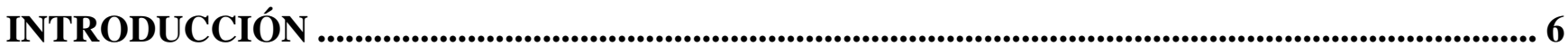

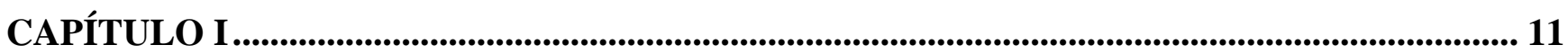

1.1. QUINE: INDETERMINACIÓN DE LA TRADUCCIÓN E INDETERMINACIÓN DE LA REFERENCIA. 12

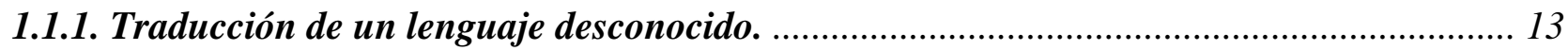

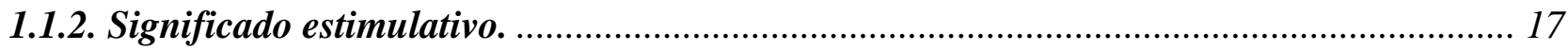

1.1.3. De la indeterminación de la traducción a la indeterminación de la referencia.................. 22

1.2. INDETERMINACIÓN DE LA REFERENCIA Y RELATIVIDAD ONTOLÓGICA................................. 29

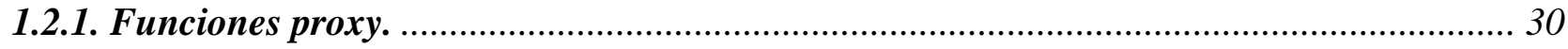

1.2.2. La relativización de la ontología como solución al problema de la indeterminación......... 33

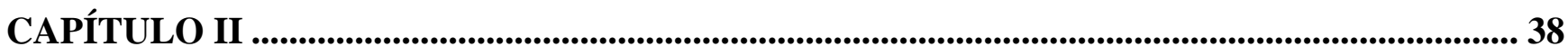

2.1. CRítica A QUiNe: IMPOSIBILIDAd DE DERIVAR LA RELATIVIDAd ONTOLÓGICA (OR) DE LA

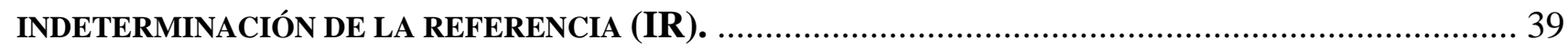

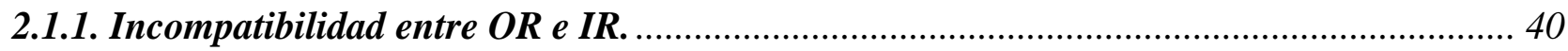

2.1.2. Convencionalismo, Instrumentalismo y relatividad ontológica.......................................... 43

2.2. FiELd, LA NOCIÓN DE REFERENCIA PARCIAL Y LA TEORÍA CAUSAL DE LA REFERENCIA. ......... 48

2.2.1. La noción de referencia parcial explicada en el contexto de un cambio de teoría............ 48

2.2.2. Referencia parcial y la teoría causal de la referencia......................................................5

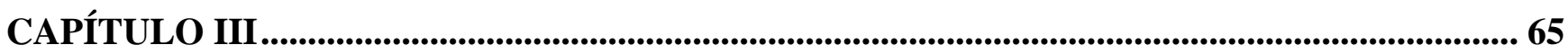

3.1. LA INCONSISTENCIA QUINEANA Y LA TEORÍA CAUSAL DE FIELD. ................................................. 66

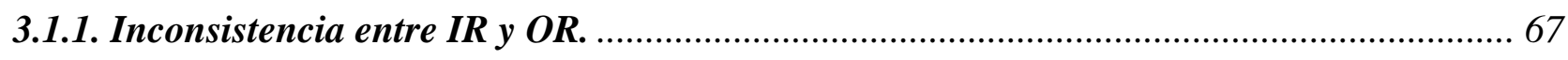

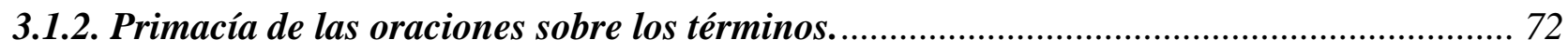

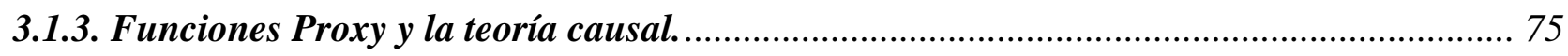

3.2. RELATIVIZACIÓN RECONSIDERADA: RELATIVIDAD DAVIDSONIANA. ......................................... 76

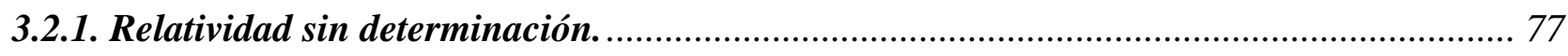

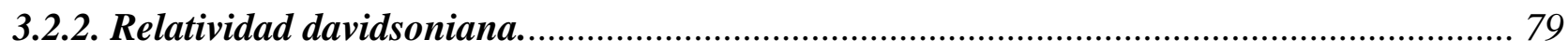

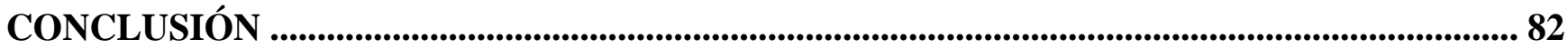

REFERENCIAS .................................................................................................................................................... 84 


\title{
INTRODUCCIÓN
}

\begin{abstract}
Staying aboard our own language and not rocking the boat, we are borne smoothly along on it and all is well; 'rabbit' denotes rabbits, and there is no sense in asking 'Rabbits in what sense of "rabbit"?' Reference goes inscrutable if, rocking the boat, we contemplate a permutational mapping of our language on itself, or if we undertake translation.
\end{abstract}

Quine

Indeterminación de la referencia e indeterminación de la traducción constituyen dos de las tesis más polémicas del filósofo W. V. Quine ${ }^{1}$. Estas tesis surgieron primeramente en oposición a la noción mentalista de significado; en general, contra toda aquella postulación de entidades semánticas no cimentada en una aproximación naturalista al lenguaje (Quine, 1969a). Equiparar el significado con una entidad mental, abstracta o de otra índole semejante entraña la adopción tácita de diversas nociones semánticas no-naturalistas: sinonimia, analiticidad, etc.; implica sobre todo la idea de determinación semántica, es decir, la noción según la cual el significado de términos, oraciones u otras expresiones está determinada. En general, los positivistas lógicos, entre los cuales destaca Carnap, mantenían esta perspectiva, la cual se manifiesta en los dos dogmas del empirismo fuertemente criticados por Quine (1953). La desconfianza hacia estas nociones supuso el principio de lo que vendrían a constituir las tesis de la IT y la IR, las cuales representan contraejemplos a la idea según la cual: “determinación del significado" constituye una noción y una herramienta legítima y útil (especialmente a la hora de hacer

\footnotetext{
${ }^{1}$ De aquí en adelante me referiré (para simplificar) frecuentemente a la indeterminación de la traducción como IT; a la indeterminación de la referencia como IR, y a la relatividad ontológica como OR.
} 
filosofía). Sin embargo, las tesis de indeterminación no han sido comprendidas del todo por los lectores (Gibson, 1998a), al contrario, han sido fuente de confusión y disputa.

En términos generales, la IT versa sobre el significado y la IR sobre la ontología, aunque ambas se encuentran íntimamente interrelacionadas. Quine, en sus primeros textos, no parece marcar una diferencia estricta entre ambas; simplemente argumenta a favor de la indeterminación de la traducción. ${ }^{2}$ Este trabajo no tiene la pretensión de rastrear paso a paso el origen y desarrollo de las tesis en cuestión, pero sí indicar algunos aspectos relevantes de esta genealogía para la consecución de la investigación. Así, me enfoco en Word and Object (1960) y Ontological Relativity (1969), pues en estas obras podemos encontrar el paso decisivo que vino a marcar la distinción entre los dos tipos de indeterminación: "In Word and Object, Quine put forward arguments in behalf of the indeterminacy of translation; in “Ontological Relativity," he pressed things further by arguing for the indeterminacy of reference as well." (Fogelin, 2004, p. 36)

La razón de examinar la relación entre ambas tesis (más específicamente, el surgimiento de la IR a partir de la IT) de indeterminación resulta de la necesidad de enmarcar y caracterizar la IR de forma adecuada. Así, la IR ocupará un lugar central en la discusión a lo largo de los capítulos del presente trabajo. Esta tesis, como ya se mencionó, ha sido objeto de disputa y confusión, y, precisamente la relación confusa entre ésta y la tesis, denominada por Quine, "relatividad ontológica" constituirá el asunto principal a tratar.

Los estudios sobre la referencia, principalmente cuando tiene lugar un cambio de teoría científica, exigen la realización de una investigación sobre la relación entre lenguaje y mundo. Quine ofrece una aproximación naturalista bastante interesante, la cual privilegia la relación entre oraciones y mundo por encima de aquélla entre palabras y objetos. Pero antes de examinar las ventajas y desventajas de la

\footnotetext{
${ }^{2}$ Pero la conciencia de la existencia de dos tipos de indeterminación no figura explícitamente en su exposición.
} 
propuesta quineana, necesitamos clarificar nociones clave como la IR y la OR y solucionar las dificultades teóricas encontradas en el camino.

El objetivo general de la presente investigación consiste en identificar los problemas que surgen como consecuencia de la conjunción IR y OR, y en mostrar una salida de corte naturalista-quineano a estas dificultades. Para este propósito, es necesario realizar distinciones y clarificar algunos conceptos e ideas. Así, 1) señalo las semejanzas y diferencias entre IT e IR; 2) muestro las razones por las cuales Quine cree que la OR funge como solución a la IR; 3) apoyándome en la obra de Field, indico la incompatibilidad IR y OR, y los problemas con las razones quineanas aducidas a favor de la conjunción; 4) presento la solución de Field a la inconsistencia y el motivo por el cual no funciona; 5) expongo como ciertas modificaciones, originalmente introducidas por Davidson (1979), a la OR nos proporcionan una noción de relativización aceptable. ${ }^{3}$

En el primer capítulo expongo como la indeterminación de la traducción y referencia surgen debido a que los únicos hechos relevantes para la determinación no alcanzan a determinar el significado ni la referencia. ${ }^{4}$ De hecho, esta última seguiría estando indeterminada aun cuando los valores de verdad de las oraciones y su significado esté determinado, o, más bien, casi completamente determinado (en la forma de sinonimia estimulativa entre oraciones, por ejemplo). El objetivo de esta exposición consiste en establecer con mayor claridad el hecho de que la indeterminación de la referencia (como fenómeno) va más allá de la indeterminación de la traducción, es decir, se trata de un caso de indeterminación más agudo (también expondré muy brevemente como la IR gana plausibilidad gracias a la reinterpretación de la ontología vía funciones proxy). Sin embargo, toda esta argumentación a favor de la IR parece llevarnos a la conclusión absurda según la cual no sabemos a qué refieren las palabras de nuestro propio lenguaje,

\footnotetext{
${ }^{3}$ Esta nueva forma de relativización nos permite evitar la inconsistencia quineana, apelando no a entidades mentales o a teorías causales, etc., sino a elementos que forman parte del mismo sistema filosófico naturalista quineano.

${ }^{4}$ En este sentido se trata de una tesis semántica-metafísica mas no epistemológica como lo sería la subdeterminación de la teoría científica por la evidencia (véase Gaudet, 2006).
} 
y es precisamente Quine quien expresa esta incomodidad. Consiguientemente, nuestro filósofo introduce la noción de relatividad ontológica a fin de subsanar el presunto sinsentido. No obstante, no es claro como la OR podría resolver el problema, pues ella misma conlleva una concepción determinista de la referencia.

En el capítulo II trato de exponer esta inconsistencia entre la IR y la OR, y para este propósito cito la crítica originalmente formulada por Hartry Field (1973), la cual dice, en general, que: la OR presupone la negación de la IR. También señalo las diferencias que Field encuentra entre la IR y otras tesis emparentadas, pues resulta útil para comprender la perspectiva de este filósofo sobre el asunto. De igual manera, expongo la noción de referencia parcial y su conexión con la teoría causal de la referencia, y como, juntas, podrían evitar la IR quineana y la OR, así como proveer de una noción de IR más apropiada que explique casos reales de indeterminación de la referencia en el contexto de un cambio de teoría científica.

Aunque la solución de Field resulta bastante atractiva, implica una noción de determinación (los términos se refieren determinadamente a por lo menos dos referentes) de la referencia, la cual está sujeta a los mismos argumentos que Quine emplea para establecer la IR. Por esta razón, en el último capítulo intento mostrar las deficiencias de la aproximación de Field, así como introducir una perspectiva más adecuada.

Davidson es quien rescata (no sin ciertas modificaciones) la conjunción IR-OR, y libra (o al menos eso argumento) a Quine de la inconsistencia. Este filósofo también explicita los problemas con la IR de Field, y la teoría causal de la referencia, y muestra cómo es que la primacía semántica de las oraciones sobre las palabras impide una solución por parte de la teoría causal. Aún más, esta teoría, lejos de resolver el problema, se ve socavada por la misma IR. 
Así, este trabajo encuentra su origen en la preocupación por solucionar la incoherencia entre IR y OR (particularmente mediante una solución naturalista-quineana), y en el camino, echar luz sobre estas tesis, así como, sobre otras nociones ligadas y su relación con las primeras. 


\section{CAPÍTULO I}

\section{LA INDETERMINACIÓN DE LA REFERENCIA Y LA RELATIVIDAD ONTOLÓGICA QUINEANAS}

Este capítulo tiene el fin de presentar de forma muy general las características fundamentales de las tesis de la IT y la IR, esclarecer en lo posible la transición de una a la otra, y como, basándonos en el sistema filosófico quineano, podemos trazar una línea divisoria entre IR y OR. Ambas empresas no son sencillas pues la conexión entre la IT y la IR no es obvia ${ }^{5}$. Asimismo, la distinción IR-OR no es clara en modo alguno en la filosofía quineana.

A lo largo del capítulo se presentarán las razones por las que Quine adopta la IR y la IT, y como llega a incomodarle la existencia de IR en nuestro propio lenguaje. Una breve descripción del experimento mental de la traducción radical resulta necesaria para poder comprender lo que lleva a Quine a adoptar tanto la IT como la IR. Este experimento mental proporciona un punto de partida a partir del

\footnotetext{
${ }^{5}$ De hecho, la interrelación entre estas nociones no es clara del todo: "There has, in fact, been considerable disagreement among writers on what Quine meant by these notions and how he related them to one another. Quine has sometimes complained that he has been misunderstood.” (Fogelin, 1996, p. 505) Por esta razón, trato de tomar la obra de Quine como guía principal.
} 
cual podemos llevar a cabo el estudio del lenguaje de forma naturalista, o al menos, constituye un intento naturalista de abordar las cuestiones semánticas. ${ }^{6}$

También veremos la solución quineana (la OR) a la IR; solución que debería acabar con el aparente absurdo según el cual no sabemos a qué refieren nuestras propias palabras, sin abandonar por ello la indeterminación de la referencia. Por último, a forma de preparación para el capítulo II, se señalarán las razones por las cuales la solución propuesta (la OR) es inconsistente con la IR y como es que el mismo Quine no se percató de esta incompatibilidad o indebidamente la paso por alto.

\subsection{Quine: indeterminación de la traducción e indeterminación de la referencia.}

Quine usa “indeterminación de la traducción” o "IT” de dos formas distintas, en un sentido amplio y uno más restringido. El sentido restringido designa la indeterminación del significado o IT; el sentido amplio comprende lo denotado por el restringido y lo designado por la etiqueta "indeterminación de la referencia" o "IR": "The indeterminacy of translation now confronting us, however, cuts across extension and intensión alike.” (Quine, 1969a, p. 35) Kirk (2004, p. 161) señala este doble uso de la expresión “Indeterminación de la traducción".

Aunque usualmente se rastrea la tesis de la IR a Word and Object (1960) e incluso más atrás a Speaking of Objects (1958), la tesis no aparece, claramente, de forma independiente sino hasta Ontological Relativity (1969a). Por consiguiente, mucha de la exposición en este capítulo y posteriores tomas estas obras como punto de partida.

\footnotetext{
${ }^{6}$ Estos constreñimientos metodológicos y teóricos que el mismo Quine impone a lingüistas y filósofos, nos llevan a la noción de "significado estimulativo", el cual corresponde a la versión de significado naturalizada. En otras palabras, el significado estimulativo constituye el tipo de significado que resulta de una investigación sistemática, susceptible de corroboración y refutación empírica, etc.; de una investigación científica sobre el significado.
} 
En lo comprendido por este capítulo me ceñiré a tratar de poner en contexto y explicar la noción restringida; después de todo, si comprendemos esta noción y la IR no tendremos ningún problema en entender la IT en su sentido amplio, en tanto esta última consiste en la conjunción de las dos primeras.

\subsubsection{Traducción de un lenguaje desconocido.}

En Word and Object (1960, p. 27), Quine define la IT de la siguiente manera: “ [...] manuals for translating one language into another can be set up in divergent ways, all compatible with the totality of speech dispositions, yet incompatible with one another". ${ }^{7}$ En otras palabras, los hechos disposicionales (las disposiciones lingüísticas de los hablantes más las estimulaciones sensoriales compartidas por lingüista y nativo), no determinan al manual de traducción: el conjunto de oraciones escogidas como traducciones de las oraciones extranjeras ${ }^{8}$ más el conjunto de instrucciones para la construcción de oraciones (una lista finita de formas lingüísticas e instrucciones para la construcción gramatical, etc., a fin de dar cuenta de la infinidad potencial de las oraciones extranjeras). El lingüista o traductor se enfrenta con una serie de disposiciones para el habla por parte del nativo dentro de un ambiente rico en estímulos sensoriales; ${ }^{9}$ su labor se centra fundamentalmente en correlacionar (traducir y/o buscar oraciones equivalentes) oraciones nativas con oraciones de su propio lenguaje. Sin embargo, la correspondencia

\footnotetext{
${ }^{7}$ La tesis de la IT conservó, para Quine, aproximadamente su forma original con el paso de los años: "two manuals could meet the dialogue and negotiation tests impeccably and yet disagree as to the admissible translations for some native sentences. They would produce translations in our language that were not equivalent to each other.” (1994a, p. 447; también véase 1990, p. 373)

${ }^{8}$ El término "manual de traducción" ostenta una significación más amplia, pues como veremos más adelante incluye la identificación y traducción de palabras; sin embargo, mientras tanto, nos restringiremos (a imitación de Quine, quien sólo más adelante implementa la traducción de términos a su concepto de manual de traducción) a oraciones.

${ }^{9}$ Las razones para restringir una concepción del significado en términos conductistas se deriva del naturalismo quineano, según el cual: "[...] mind, and meaning are part of the same world that have to do with, and that they are to be studied in the same empirical spirit that animates natural science. There is no place for a prior philosophy." (Quine, 1969, p. 26) De hecho, este mismo naturalismo sustenta en última instancia la IT en un sentido amplio (y, por tanto, la IR): "When with Dewey we turn thus toward a naturalistic view of language and a behavioral view of meaning, what we give up is not just the museum figure of speech. We give up an assurance of determinacy" (Quine, 1969, p. 28) y: "For naturalism the question whether two expressions are alike or unlike in meaning has no determinate answer, known or unknown, except insofar as the answer is settled in principle by people's speech dispostitions”. (Quine, 1969, p. 29)
} 
entre oraciones no está completamente determinada, sino más bien indeterminada (al menos, parcialmente). Se trata de una tesis sobre la inexistencia de hechos que la determinen. No deben interpretarse estas tesis (IT e IR) como tesis epistemológicas (véase Gibson, 1998a, pp. 139-54 y Gaudet, 2006; Friedman, 1975). Pues, si bien Quine se apoya en la tesis de la subdeterminación de la teoría por la evidencia empírica para sustentar la IT (Putnam, 1975, p. 179), la IT es propiamente una tesis semántica. ${ }^{10}$ En la descripción anterior se destacan cuatro componentes básicos de la traducción tal cual la imagina Quine: 1) estimulaciones sensoriales (concurrentes al nativo y al traductor); 2) disposiciones para el comportamiento verbal, y 3) búsqueda de una oración equivalente a la proferida por el nativo. Por último (este elemento constituye un componente más bien metodológico, en cambio los primeros tres conforman los datos objetivos para la traducción. También puede vérsele como un componente de 3)), 4) traducción de los conectivos lógicos. Esta última nos permite traducir compuestos de oraciones. Los elementos aquí señalados dejan entrever la escasez de recursos a disposición del traductor (no cuenta con intérpretes, él mismo no es bilingüe, no existen cognados que faciliten la labor de traducción, no se

\footnotetext{
${ }^{10}$ En este trabajo resulta imposible identificar y analizar las diferencias entre una tesis epistemológica y una ontológica, sin embargo baste mencionar algunos puntos cruciales para entender tal distinción. La IT implica que no existe un fact of the matter que nos permita decidir entre dos manuales de traducción que se acoplan a los hechos relevantes (las disposiciones al comportamiento verbal). Por otro lado, la tesis epistemológica que figura en la filosofía quineana, y está ligada de una u otra forma a la IT, la subdeterminación de la teoría por la evidencia o UT señala la laguna existente entre la evidencia empírica (oraciones observacionales) y la teoría (oraciones teóricas), pero no nos dice nada sobre existencia o no existencia (sobre una laguna ontológica): "Underdetermination of theories does not imply that there is no fact of the matter" (Gaudet, 2006, p. 38). La UT únicamente señala como nuestras teorías sobre el mundo trascienden toda observación posible (evidencia) de forma que pueden formularse dos o más teorías lógicamente incompatibles sobre la misma evidencia empírica. Sin embargo, la UT no implica la inexistencia de un fact of the matter, de hecho, si una teoría es verdadera "there is always a fact of the matter." (Gaudet, 2006, p. 38), "In the case of natural science, on the other hand there is a fact of the matter, even if all possible observations are insufficient to reveal it uniquely. The facts of nature outrun our theories as well as all possible observations, whereas the traditional semantics outruns the facts of language." (Gaudet, 2006, p. 66)

Decimos de un manual de traducción que es correcto porque "there is a behavioral fact of the matter (which depends on physical microstates) to its rightness)." (Gaudet, 2006, p. 54) Pero si dos manuales son correctos, es decir, se ajustan a todas las disposiciones verbales (a los facts of the matter), entonces, dado que ya hemos echado mano de todos los facts of the matter, no existe un fact of the matter que nos permita elegir a un manual como "el correcto".

IT y UT constituyen dos teorías distintas; la primera semántica, la segunda epistemológica. Incluso la IT es adicional: “Thus the indeterminacy of translation is an indeterminacy additional to the underdeterminacion of nature." (Quine, 1987, p. 10) Y "Indeterminacy of translation is a claim about the nature of language beyond and above underdetermination of theory." (Gaudet, 2006, p. 69)
} 
comparte una cultura en común etc.), y precisamente esta situación desfavorable conviene a Quine para mostrar con mayor claridad los problemas inherentes en la traducción y la verdadera importancia de conceptos semánticos como significado, sinonimia, oración, etc. A este experimento mental (no completamente alejado de situaciones reales) Quine le denomina: traducción radical. Lo polémico resulta de la conclusión extraída de esa situación: las disposiciones verbales y las estimulaciones sensoriales no determinan la traducción de las oraciones nativas. En otras palabras, dadas dos (o más) traducciones distintas, lo único que tenemos (las estimulaciones y las disposiciones para el comportamiento verbal) para decidir entre esas dos traducciones no nos capacitan para realizar tal elección. La traducción radical nos deja indecisos sobre la adecuación de uno u otro manual; nos deja con IT. ${ }^{11}$

Quine señala diversas características de la estimulación sensorial (el primer componente de la traducción radical, mencionado arriba). Aquí mencionaremos las más importantes, a fin de dar una idea general del ámbito semántico donde surge la IT. La estimulación puede abarcar todos los sentidos (vista, oído, olfato, gusto y tacto), aunque sólo uno de ellos puede llevar la mayor carga. Las estimulaciones difieren dependiendo del sentido y presentan propiedades específicas acordes. Sin embargo, Quine no presta demasiada atención a estas divergencias, más bien introduce conceptos de mayor generalidad (y utilidad) como módulo de estimulación, centro y periferia del patrón irradiación ocular (lo que el ojo ve), etc. La noción de módulo juega un papel primordial pues indica el ingreso y/o exclusión de patrones estimulativos (estimulaciones sensoriales). Su utilidad reside en que permite calcular la cantidad de estímulos asociados a una oración o disposición verbal; y, como veremos, la noción semántica quineana necesita de estímulos asociados a oraciones. La estimulación surge debido al contacto (se trata, para ser preciso, de la disposición de un sujeto a asentir o disentir de una oración proferida, dado cierta

\footnotetext{
${ }^{11}$ Cabe señalar que la IT sucede no sólo en el contexto de la traducción radical, sino también en casa: "I have directed my indeterminacy thesis on a radically exotic language for the sake of plausibility, but in principle it applies even to the home language.” (Quine, 1992a, p. 48)
} 
estimulación) entre nosotros y el mundo (no entre objetos) $)^{12}$ y constituye un componente fundamental del significado en su versión quineana: significado estimulativo.

Las disposiciones al comportamiento verbal -dado un ambiente rico en estimulaciones sensoriales- también son elementos indispensables para entender la labor de traducción. Las disposiciones están ligadas y dependen, para su génesis y conservación, siempre de la estimulación sensorial; de no haber estimulación no existiría disposición, al menos no con respecto al mundo (con respecto a las estimulaciones que nos vienen del mundo). Sin embargo, si no existe disposición con respecto al mundo: difícilmente podríamos explicar (al menos de forma naturalista) en qué consiste el significado de nuestras oraciones, o del lenguaje en general. Por otro lado, en lugar de hablar de disposiciones al comportamiento verbal, quizás deberíamos hablar simplemente de comportamiento verbal. Sin embargo, la noción de disposición rescata la naturaleza potencial-actual (cabe mencionar que con el término "disposición” nos referimos a estados fisiológicos subyacentes [Quine, 1975]) del lenguaje. $^{13}$

La traducción de oraciones nativas depende de la evidencia (disposiciones al comportamiento verbal más estimulaciones sensoriales). Sin embargo, si queremos traducir compuestos de oraciones, requerimos haber establecido, de antemano, la traducción de las partículas lógicas. La traducción de los conectivos lógicos “y”, “o”, “si...entonces”, etc., va ligada a la traducción de oraciones. Una vez que contamos con algunas oraciones traducidas comenzamos a formar compuestos con ellas. La traducción de estos compuestos nos permite traducir los conectivos en base al asentimiento o disentimiento del

\footnotetext{
${ }^{12}$ No debe confundirse "estimulación” con "dato-sensorial”, los segundos corresponden a entidades (por lo demás, inaceptables desde un punto de vista naturalista).

${ }^{13}$ Así: "His starting point, in thinking about meaning, is the use of language [...] his focus is on the assertion of sentences, both the assertions actually made and those that would be made under various specifiable circumstances." (Hylton, 2007, p. 65) Por otro lado, el lenguaje no permanence siempre el mismo: "What we objectively have is just an evolving adjustment to nature, reflected in an evolving set of dispositions to be prompted by stimulations to assent to or dissent form sentences." (Quine, 1960, p. 38)
} 
hablante respecto a los compuestos de oraciones. Por ejemplo, si el hablante asiente a la conjunción de dos o más oraciones, traducimos la partícula lingüística recurrente como nuestra "y"; si disiente de una oración a la que se ha añadido cierta expresión, traducimos la partícula recurrente como “no” (negación), y así con los demás conectivos. Esta labor de traducción implica cierta empatía ${ }^{14}$ por parte del traductor, en tanto asume que el nativo comparte conectivos lógicos similares a los suyos (el lingüista presupone la racionalidad de los nativos), que se rigen por las tablas de verdad.

\subsubsection{Significado estimulativo.}

El significado estimulativo corresponde a la versión naturalizada del significado propuesta por Quine. Así, según Quine (1969a, p. 29): “there are no meanings, nor likenesses nor distinctions of meaning, beyond what are implicit in people's dispositions to overt behavior". Una vez que contamos con estimulaciones sensoriales y disposiciones para el comportamiento verbal, podemos definir el significado estimulativo como el conjunto de estimulaciones sensoriales correlacionadas con la disposición verbal y oración correspondientes ${ }^{15}$. En otras palabras: “The stimulus meaning is a full crosssection of the subject's dispositions to assent or to dissent form a sentence." (Quine, 1960, p. 36) Para simplificar las cosas, siguiendo a Quine, conviene más hablar de correlaciones entre estimulaciones y oraciones. Después de todo, la proferencia de una oración por una persona dada cierta estimulación implica cierto hábito lingüístico o disposición al comportamiento verbal por parte del individuo: “An episode of assent is not itself a disposition; rather, the method of querying is a means to discovering those dispositions. (Kemp, 2006, p. 41) Quine (1960, p. 34) define el significado estimulativo para una persona de la siguiente manera: "The stimulus meaning of a sentence for a subject sums up his disposition to assent to or dissent from the sentence in response to present stimulation" e introduce una noción de sinonimia basándose en el concepto de significado estimulativo: sinonimia estimulativa. La sinónima

\footnotetext{
${ }^{14}$ Davidson extiende este principio de reciprocidad a toda la labor interpretativa.

${ }^{15}$ El significado estimulativo, en tanto depende de la estimulación sensorial, depende del módulo.
} 
consiste, pues, en la equivalencia entre significados estimulativos. Ciertamente la versión naturalizada de Quine impide una relación sinonímica absoluta como lo requiere la noción usual de sinonimia. Asimismo la noción de significado estimulativo no equivale a la noción tradicional de significado. Las razones aducidas, aunque no las abordaremos aquí, dependen de la conexión -aparentemente necesariaentre significado estimulativo e información colateral, o lenguaje previamente adquirido (las oraciones fijas mantienen numerosas conexiones inferenciales con la información colateral) (véase Quine, 1960, p. 39-40). De hecho, Quine prefiere hablar de equivalencia aproximada entre significados estimulativos que en sinónima per se. ${ }^{16}$ (Ya en Carnap and Logical Truth [1954, p. 129], este filósofo mantenía una posición gradualista ${ }^{17}$ ).

Ahora bien, la asociación de oraciones con estimulaciones sensoriales se da en dos niveles distintos: de forma más o menos directa y de forma más o menos indirecta a través de otras oraciones, es decir: algunas oraciones guardan una estrecha relación con la experiencia o estimulaciones, mientras que otras sólo se relacionan indirectamente a través de conexiones con otras oraciones, algunas de las cuales están conectadas directamente con la experiencia. Aunque Quine no es muy claro sobre la importancia relativa del significado estimulativo para cada una de las oraciones del lenguaje -se encuentren ligadas directamente a la estimulación o no-, consiente indiscutiblemente el predominio del significado estimulativo en las oraciones directamente conectadas con la experiencia ${ }^{18}$. No profundizaremos en el tema aquí, pero vale la pena mencionar algunos más de los conceptos clave que Quine usa para enmarcar el contexto de traducción y los resultados favorables y no tan benignos para la traducción, significado, la referencia, etc.

\footnotetext{
${ }^{16}$ De hecho, según Quine (1969a, p. 30) "See language naturalistically, on the other hand, and you have to see the notion of likeness of meaning in such a case simply as nonsense."

17 "One quickly identifies certain seemingly transparent cases of synonymy [...] conceivably the mechanism of such recognition, when better understood, might be made the basis of a definition of synonymy and analyticity in terms of linguistic behavior. On the other hand such an approach might make a sense only of something like degrees of synonymy and analyticity."

${ }^{18}$ Las oraciones obervacionales ostentan significado estimulativo en el más alto nivel.
} 
Se distinguen diversos tipos de oraciones: oraciones ocasionales, oraciones fijas (standing sentences), oraciones observacionales, oraciones no-observacionales (estas últimas admiten de grados de observación; al menos para el Quine de Word and Object). Las oraciones ocasionales corresponden a aquellas que demandan asentimiento o disentimiento cuando son proferidas dada una estimulación apropiada. Las oraciones fijas también responden a la experiencia, pero a diferencia de las oraciones ocasionales, su valor de verdad no depende totalmente de la estimulación presente en cierta ocasión. ${ }^{19}$ Cuando la conexión oración-estimulación es muy cercana estamos hablando de oraciones observacionales (éstas constituyen el punto de entrada al lingüista para realizar la traducción); ${ }^{20}$ si no, de oraciones no-observacionales. Sin embargo, no existe una delimitación nítida entre oraciones observacionales y no-observacionales. ${ }^{21}$ Quine, al no proveernos de un criterio de demarcación, apoya la idea de una gradación de oraciones observacionales o "gradación de la observacionalidad” (véase Quine, 1960, p. 42 y 69 y Kirk, 2004, p. 162). Sin embargo, por razones de simplicidad -siguiendo a Quinehablaremos de oraciones observacionales queriendo referir a aquel conjunto que intuitivamente consideramos suficientemente cercano a la experiencia; y de oraciones fijas para el grupo opuesto.

Esta distinción entre lo observacional y lo no-observacional nos permite señalar algunas distinciones sutiles sobre el significado estimulativo. Como se mencionó arriba, el significado estimulativo hace, de alguna manera, más justicia al contenido semántico de oraciones más observacionales. En algún sentido, podríamos hablar de determinación: el significado estimulativo determina casi cabalmente al contenido semántico de la oración. ${ }^{22}$ Existe una interconexión entre el

\footnotetext{
${ }^{19}$ Las oraciones, "[...] the less susceptible they are to prompted assent and dissent, the fewer clues are present in stimulus meanings. The notion of stimulus meaning is thus most important for occasion sentences." (Quine, 1960, p. 36-7)

${ }^{20}$ También constituyen el punto de partida para el niño en el aprendizaje de su lengua materna.

${ }^{21}$ Ciertamente la distinción no es tajante en Word and Object: "Degrees of approximation to stimulus-analyticity, as well as degrees of observationality, would be allowed for in a truer account" (p. 69) pero en obras posteriores, se acentúa la división cuando se habla de oraciones consideradas de forma holofrástica y oraciones teóricas (por ejemplo en 1995; 1981b)

22 "[...] their stimulus meanings may without fear be said to do full justice to their meanings.” (Quine, 1960, p. 42; veáse también, p. 63), también en las oraciones observacionales "[...] it is where meaning is firmest [...] The observation sentence, situated at the sensory
} 
significado estimulativo y el grado de observacionalidad, y una de las consecuencias inmediatas indica una proporcionalidad directa entre el aumento de observacionalidad y el de significado estimulativo, y viceversa.

La metáfora de la red de creencia, o, para ser más preciso, de la red de significado nos ayuda a entender la teoría semántica quinenana. El lenguaje está conformado por oraciones, las cuales forman una red semántica, ligadas unas con otras de múltiples y complejas formas a través de conexiones inferenciales (Quine, 1960, p. 11). Este complejo tejido de oraciones se relaciona con la experiencia (o estímulos sensoriales) sólo en la periferia, ${ }^{23}$ y desde ahí reciben todas las demás oraciones contenido semántico estimulativo gracias a las conexiones entre oraciones: ${ }^{24}$ "Factuality provides meaning and evidence to theoretical sentences indirectly, that is, via the multifarious relations that those sentences have with observation sentences." (Gaudet, 2006, p. 37) Hylton expresa este punto de la siguiente manera:

An observation sentence is directly linked to stimulations, and those links determine its correct use and thus its meaning. For a nonobservation sentence, links to stimulations are equally important, but in this case those links are partly or wholly indirect. The sentence is linked to other sentences that are in turn linked

periphery of the body scientific, is the minimal verifiable aggregate; it has an empirical content all its own and wears it on its sleeve." (1969b, p. 89) Sin embargo, en Word and Object Quine mantiene una noción gradualista de oración observacional. En escritos posteriores parece cambiar de opinión. La modificación hecha me parece motivo de debate, pero tal polémica se apartaría de los asuntos principales aquí tratados.

${ }^{23}$ Las oraciones observacionales son las más cercanas a la experiencia y son las que dotan de contenido empírico al lenguaje o nuestra teoría sobre el mundo.

${ }^{24}$ Entre más teóricas sean las oraciones, su significado será estimulativo en menor medida: "Many sentences are more deeply theoretically embedded [...] so that, the observable circumstances that affect our acceptance or rejection of them may be extremely remote from anything that would ordinarily be thought of as their meaning." (Hylton, 2002, p. 15). Así, la oración de una sola palabra "Soltero" "is inculcated through connections with other sentences, linking up thus indirectly with past stimulations of other sorts than those that serve directly to prompt present assent to the sentence, then its stimulus meanings will vary with the speakers' pasts, and the sentence will count as very unobservational. The stimulus meaning of a very unobservational occasion sentence for a speaker is a product of two factors, a fairly standard set of sentence-to-sentence connections and a random personal history; hence the largely random character of the stimulus meaning from speaker to speaker.” (Quine, 1960, p. 45) 
to other sentences and so on, terminating in observation sentences. This terminus provides the empirical meaning for any sentence, however indirect and complex the connections may be. (2004, p. 236)

Asimismo, Gaudet (2006, p. 40) declara: “The relations between the theoretical sentences and the observation sentences constitute both the meaning of and the evidence for the theoretical sentences," "Theoretical sentences' "meanings" and evidence are the theoretical sentences' relations (holistic) with observation sentences." (Gaudet, 2006, p. 36) ${ }^{25}$

La interdependencia semántica entre oraciones se hace evidente cada vez más conforme traducimos más y más oraciones, especialmente aquellas menos observacionales. La traducción de una oración requiere, ahora, el reajuste en la traducción de otras oraciones. Podemos emparejar oraciones nativas con sus respectivas traducciones, siendo estas últimas incompatibles entre sí. Sin embargo, la compatibilidad con la experiencia de ambos manuales de traducción se conserva siempre y cuando ajustemos otras oraciones del sistema (véase Kemp, 2006, p. 36). Ese holismo semántico aparece como un argumento crucial a favor de la IT: "The crucial consideration behind may argument for the indeterminacy of translation was that a statement about the world does not always or usually have a separable fund of empirical consequences that it can call its own.” (Quine, 1969b, p. 82). Incluso Quine "himself refers to his meaning holism as the thesis of the indeterminacy of translation." (De Rosa y Lepore, 2004 p. 66, 71)

Otra noción que se mencionará de paso es “oración analítica” (por ejemplo: “Soltero”, o vocablos teóricos [considerados como oraciones] científicos como "Masa"). Este tipo de oraciones rescatan la

\footnotetext{
${ }^{25}$ Además de este holismo semántico, existe un holismo confirmacional adoptado tanto por Quine como por Duhem antes que el primero (aunque tenían ideas ligeramente distintas al respecto) (véase Vuillemin, 1986). Este último hace referencia a la necesidad de confrontar nuestra teoría global del mundo (o una parte suficientemente grande) con la evidencia empírica (y, por consiguiente, la imposibilidad de confirmar oraciones aisladas con la experiencia). De hecho, es creencia corriente que el holismo semántico es una consecuencia directa del holismo confirmacional más una teoría verificacionista del significado (que Quine parece sostener. Sin embargo, tal discusión va más allá de objetivos de este trabajo) (véase Fodor y Lepore, 1992, p. 41; Block, 1998).
} 
vieja noción de analiticidad, aunque sólo de forma parcial. Más bien, se trata de una noción de analiticidad naturalizada (pertenecen a uno de los extremos donde el grado de observacionalidad es casi nulo), donde una oración cuenta como analítica si un hablante muestra siempre la misma disposición a asentir o disentir de dicha oración sea cual sea la estimulación. Esto no significa que la oración analítica está completamente disociada de la experiencia, aunque si se encuentra muy alejada de ella. Este tipo de oraciones se aprenden a través de las conexiones de palabras con palabras; la red semántica nos permite comprender, en última instancia, el significado de la expresión. ${ }^{26}$

Cabe mencionar que las nociones semánticas quineanas fundamentales, hasta ahora introducidas, pueden concebirse de distintas formas, dependiendo de su grado de socialización; del grado en que estos fenómenos lingüísticos han sido creados y modificados por la interacción humana. El significado estimulativo y la sinonimia estimulativa ${ }^{27}$, así como la observacionalidad pueden definirse para un individuo en particular (por ejemplo, sinonimia intrasubjetiva) o para una comunidad. Pero, siempre prevalece un elemento social en dichos conceptos, pues el lenguaje nace de la comunicación humana. ${ }^{28}$ Ciertamente existen diferencias sutiles, y éstas sirven para distinguir y clasificar diversas características del significado, la estimulación, etc., aunque el asunto puede entenderse como una cuestión de grados.

\subsubsection{De la indeterminación de la traducción a la indeterminación de la referencia.}

¿Cómo se relaciona lo anterior con la IR? Bueno, se trata nada menos que de la relación entre la IT y la IR. Aunque el Quine de Word and Object y Speaking of Objects no es muy claro al respecto,

\footnotetext{
${ }^{26}$ El significado depende, también, de la red: "The empirical meaning of such a sentence is not exhausted by its links to stimulations." (Hylton, 2004, p. 135)

${ }^{27}$ La sinonimia estimulativa, pero sobre todo su significado estimulativo, de términos muy alejados de la observación, por ejemplo: "presidente" dependen de conexiones con otras oraciones, algunas de las cuales son oraciones observacionales. El significado estimulativo de oraciones teóricas se encuentra en éstas sólo de forma indirecta: "The sparseness of its stimulus meaning is no sparseness of meaning intuitively speaking, but has the effect that stimulus meaning fails to do the sentence much justice.” (Quine, 1960, p. 63)

${ }^{28}$ La noción socializada del lenguaje, le presenta como "una serie de disposiciones verbales socialmente inculcadas, frente a un conjunto de estimulaciones apropiadas.” (Quine, 1960)
} 
podemos encontrar en esas obras los primeros pasos hacia la formulación de la IR (y, quizás, también de la OR). Ahí, Quine intenta extraer la noción de sinonimia de términos a partir de la sinonimia de oraciones; sin embargo, se enfrenta a diversas dificultades.

1) La sinonimia estimulativa entre oraciones no implica la coextensión de términos. ${ }^{29}$

2) La coextensión de los términos no implica la sinonimia estimulativa entre oraciones.

En el caso (1) tenemos que la sinonimia estimulativa entre "Conejo" y "Gavagai” (tomando el ejemplo de Quine, 1960, p. 51) no garantiza la coextensión de los términos “conejo" y "gavagai”. ${ }^{30}$ Supongamos que contamos con una noción clara de coextensión de términos (véase Gibson, 1982, p. 70). Aun cuando exista la sinonimia estimulativa entre las oraciones mencionadas, el lingüista cuenta con libertad para traducir "gavagai” como refiriéndose a: $\operatorname{conejos}^{31}$, partes-no-separadas-de-conejo, periodostemporales-de conejo, o al conjunto de todos los conejos existentes, o a la conejeidad. ${ }^{32}$ Considérese el caso (2). La coextensión de los términos (por ejemplo) "nilo" y "nahal" no implica la sinonimia estimulativa entre las oraciones correspondientes. Supóngase que el lingüista $P$, quien no conoce el río Nilo (no conoce ni su origen ni su desembocadura), recorre territorios africanos circundantes al Nilo (aunque no a lo largo de las orillas del río), y en algún punto del Cairo su compañero le dice que el río frente a ellos se llama "Nilo". Más adelante, en la ciudad de Jina (Uganda) pregunta a un nativo de la ciudad por el nombre del río; este le responde "Nahal". En ambos casos el lingüista ha visto el mismo río, pero ha recibido estimulaciones sensoriales distintas (diferente ángulo, diferencias visuales debidas

\footnotetext{
${ }^{29}$ Incluso "Intrasubjective stimulus synonymy, for all is advantages over the two-speaker case, is similarly powerless to equate terms." (Quine, 1960, p. 54)

30 “Conejo" es una oración del español de una sola palabra que también podemos expresar como "He ahí un conejo". "Gavagai” es la oración nativa para "Conejo". Asimismo, "gavagai” es la traducción al lenguaje nativo de nuestro término "conejo".

${ }^{31}$ Véase Quine, 1976b, pp. 124-5 para ver la concepción quineana de objeto material.

${ }^{32}$ Los hechos objetivos no determinan si debemos traducir expresiones como términos generales, singulares, etc. Por ejemplo, la palabra "greede" puede traducirse como refiriéndose al color verde (en este caso "greede" sería un término singular abstracto), el cual es un objeto abstracto; al verde instanciado en diversos objetos (entonces "greede" sería un término general concreto), o a objetos concretos. (Véase Quine, 1969a, pp. 38-9, y también Quine 1960, pp. 52-3).
} 
a la diferente anchura del río y variación en el color de sus aguas, etc.). Consiguientemente, el que dos términos se refieran a uno y el mismo objeto no implica sinonimia en los estímulos sensoriales; sinonimia estimulativa entre las oraciones correspondientes. ${ }^{33}$

De hecho, la situación imaginada en el caso (2) ni siquiera puede comenzar si aceptamos, con Quine y Davidson, la primacía semántica de las oraciones sobre los términos (véase capítulo III). Ahora comenzamos a entrever como la IR empieza a tomar forma propia; como ya en Word and Object (e incluso antes en Speaking of Objects) Quine contaba al menos con una proto-noción de la IR: “The gavagai example was at best an example only of the inscrutability of terms, no of the indeterminacy of translation of sentences.” (Quine, 1970, p. 182)

Así:

We could equate a native expression with any of the disparate English terms 'rabbit', 'rabbit stage', 'undetached rabbit part', etc., and still, by compensatory juggling the translation of numerical identity and associated particles, preserve conformity to stimulus meanings of occasion sentences. (Quine, 1960, p. 54)

La oración de una sola palabra "Conejo" puede expresarse, también, como "He ahí un conejo". Por otro lado, como puede apreciarse por la estructura de la oración “Conejo” (a saber: he-ahí-un-conejo), el término "conejo" constituye un elemento de ésta. Según Quine, la IR permite que reinterpretemos la ontología del término “conejo" (asignándole como referente, todos los conejos del mundo, la conejeidad, etc.), sin que por ello sea afectado el significado estimulativo de la oración "He ahí un conejo". Sin embargo, para lograr este resultado debemos modificar las demás partículas de la oración de forma que

\footnotetext{
$33 \mathrm{Ni}$ siquiera la sinonimia estimulativa para un solo individuo, o sinonimia estimulativa intrasubjetiva determina la referencia: "Intrasubjective stimulus synonymy, for all its advantages over the two-speaker case, is similarly powerless to equate terms.” (Quine 1960, p. 54)
} 
a cada reinterpretación ontológica corresponda una modificación compensatoria en las otras partículas constitutivas de la oración.

De esta manera, bajo una reinterpretación de la ontología del término “conejo” en la oración "He ahí un conejo" arribamos al término "partes-no-separadas-de-conejo". Para compensar la reinterpretación, debemos modificar algunas partículas de la oración. El artículo indefinido masculino “un” se elimina (en español) y se reescribe en su lugar el artículo indefinido femenino "una”. La identidad numérica del término no cambia al plural, pues “conejo" y “parte-no-separada-de-conejo" refieren a una sola cosa (no a una pluralidad de entidades). Así, una vez realizados los cambios pertinentes, la oración "He ahí una parte-no-separada-de-conejo" reemplazaría a la primer oración "He ahí un conejo" conservando el mismo significado estimulativo. La ontología ha variado pero no el significado.

El caso "gavagai" tal vez se encuentre algo lejano de la situación real de traducción. Por ello, Quine (1969a, p. 36) introduce el ejemplo de los clasificadores japoneses. Creo que este caso puede aclarar un poco más el punto de la IR. Los clasificadores japoneses se ligan a numerales o a términos, contamos pues con tres elementos (expresiones o términos) en una oración japonesa de este tipo, representémosla como $\mathrm{ABC}$, donde, $\mathrm{A}$ : clasificador; $\mathrm{B}$ : numerador y C: término. Una expresión japonesa sobre animales (bovinos en este caso), puede traducirse como refiriendo al objeto 5 cabezas de ganado: B-AC, donde el clasificador A va ligado al término C. O bien puede traducirse como refiriéndose al objeto 5 bueyes: BA-C, donde el clasificador va ligado al numerador e indica el género del animal. ${ }^{34}$ Así, Quine muestra como la referencia está indeterminada siempre y cuando hagamos suficientes cambios compensatorios en otras partes de la oración: "These are two very different ways of treating the third Japanese word; and the three-word phrase as a whole turns out all right in both cases only because of compensatory differences in our account of the second word the classifier.” (Quine, 1969a, p. 37) En el

\footnotetext{
${ }^{34}$ Por cuestiones de claridad presento las expresiones en el orden BAC, pero en japonés el orden de los términos es diferente. Para mayor información véase: Bunt, 2002, p. 194-7.
} 
primer caso, se trata de un término de masa; en el segundo se habla de objetos específicos. En ambos casos, nos referimos a cosas distintas, en el sentido de que dividimos la referencia de distintas formas cada vez. Los ajustes compensatorios tienen lugar entre términos y predicados y son mandatorios pues el significado de estos segmentos depende de su rol en la oración como un todo: "words can still be said to owe their meaning to their roles in sentences." (Quine, 1992a, p. 37)

La IT y la IR comparten muchas cosas en común, entre ellas: 1) la traducción de expresiones de un lenguaje a otro están indeterminadas (incluso en el propio lenguaje) pues diferentes (dos o más) manuales de traducción se ajustan a las estimulaciones sensoriales o al significado estimulativo de oraciones observacionales; 2) la indeterminación no imposibilita la comunicación, "Indeterminacy means not that there is no aceptable translation, but that there are many" (Quine, 1987, p. 345; reply to Vuillemin, p. 622); 3) incluso el problema de la indeterminación de la traducción de oraciones y términos empieza al mismo tiempo. En el caso de la IT, el lingüista llega a la conclusión de que existe por lo menos un manual de traducción tan bueno como el suyo; en el caso de la IR ¿Qué sucede?

Según Quine, el lingüista cuenta con varias hipótesis analíticas igualmente adecuadas (o sistemas de hipótesis analíticas), las cuales consisten en segmentar la oración en varias partes o palabras, y traducirlas o correlacionarlas con palabras de nuestro idioma. ${ }^{35}$ Por ejemplo, el lingüista nota en algún momento que cierto sonido siempre acompaña una o varias oraciones sólo cuando se encuentra el color rojo dentro de las estimulaciones visuales. Luego, el traductor asume que tal sonido refiere al color rojo. Generalmente el lingüista empieza a distinguir sonidos recurrentes en diversas oraciones (consideradas anteriormente de forma holofrástica, es decir como complejos sin ningún tipo de estructura interna). Lo anterior implica asignar una referencia a lo que nosotros creemos constituyen las palabras nativas. Por regla general, la referencia asignada corresponde a aquella denotada por nuestras propias palabras

\footnotetext{
35 Tentativamente, pues no existe un hecho objetivo que indique la forma correcta de segmentar la oración; el lingüista suele hacer uso de su creatividad (Quine, 1958), guiada, por lo general, por consideraciones de simplicidad y costumbre.
} 
(desgraciadamente la referencia de nuestras palabras no parece, tampoco, estar determinada del todo). Sin embargo, podríamos asignarle alguna otra u otras, y el significado estimulativo permanecería intacto (véase Quine, 1960 pp. 51-2): “We can assign the same stimulus meaning to a sentence $s$ by interpreting its components in different ways." (Glock, 2003, p. 174) De hecho, "we could know the necessary and sufficient stimulatory conditions of every possible act of utterance in a foreign language, and still not know how to determine what objects of that language to believe in.” (Quine, 1958, p. 12)

Creemos que los términos del nativo denotan objetos similares a los denotados por nuestras propias expresiones. Sin embargo (como bien nota Quine, 1958, 1960), ello parece deberse, más bien, a nuestra tendencia a imponer la ontología local; creemos y postulamos que el nativo se refiere a lo que nosotros acostumbramos nombrar dadas ciertas circunstancias experienciales. ${ }^{36}$

La creación de hipótesis analíticas o, lo que es lo mismo, la traducción de términos de un lenguaje desconocido al nuestro requiere tomar en cuenta la traducción de lo que Quine llama el aparato de individuación. Éste comprehende los cuantificadores universal y existencial, las terminaciones en plural, la identidad, etc. ${ }^{37}$ De hecho, antes de poder diferenciar términos (“conejo" y "partes-no-separadas-deconejo", por ejemplo), el lingüista debe ser capaz de preguntar al nativo en su lengua por la diferencia entre las extensiones de dichas expresiones. Sin embargo, tal acción no tendría lugar si antes no traducimos la partícula para la identidad nativa. En otras palabras, para preguntar al nativo por la diferencia entre "conejo" y "partes-no-separadas-de-conejos" debemos contar con la traducción de "es" de la identidad, pero ¡la traducción de esta partícula también está indeterminada! ${ }^{38}$ Nos encontramos,

\footnotetext{
${ }^{36}$ No se descarta que la experiencia no determine en absoluto la referencia, sin embargo, el efecto de la experiencia sobre nuestros hábitos de reificación es mínimo; al menos comparado con aquél sobre las oraciones.

${ }^{37}$ El aparato individuativo está constituido por: el "es" de la identidad (y derivados: “el mismo", “otro", etc.), numerales, pronombres y terminaciones en plural. La traducción del aparato individuativo requiere de hipótesis analíticas; la traducción de palabras y el aparato de individuación van de la mano (véase Quine, 1969, p. 33).

${ }^{38}$ Porque "if one workable overall system of analytical hypotheses provides for translating a given native expression into "is the same as," perhaps another equally workable but systematically different system would translate that native expression rather into something like “belongs with.” (Quine, 1969, p. 33), y: “If by analytical hypothesis we take 'are the same' as translation of some construction in the jungle
} 
aquí, con una conexión manifiesta entre IT e IR: la IT del aparato referencial desemboca en la IR; el significado estimulativo no nos indica un único aparato individuativo. ${ }^{39}$ De hecho, la traducción de la referencia y del aparato individuativo constituyen las dos caras de la misma moneda; ambas cuestiones son interdependientes, si se resuelve una se resuelve la otra.

El conjunto de hipótesis analíticas más la traducción de los diferentes tipos de oraciones y los conectivos lógicos constituyen el manual de traducción del lingüista. Sin embargo, en vista de la escasez de recursos para llevar a cabo la traducción, llegamos a la conclusión de que necesariamente la traducción de oraciones está indeterminada, así como la de los términos. Los elementos objetivos esenciales (únicos elementos disponibles para el traductor radical) en la traducción radical: 1) estimulación sensorial y 2) disposiciones del hablante, no determinan una única traducción, es decir: el significado de las oraciones está indeterminado. Lo mismo vale para la referencia. Sin embargo, la IR va un poco más allá, pues no sólo 1) y 2) no determinan la referencia, ni siquiera la casi absolutamente determinada naturaleza del significado (estimulativo) de las oraciones observacionales determina la referencia. ${ }^{40}$ Aunque en esta situación podemos hablar de mayor determinación del contenido semántico de las oraciones, la indeterminación de la referencia persiste prácticamente inmutable (la indeterminación del significado también, pero en menor grado). Podemos, como veremos más abajo, sin ningún problema, aplicar una función proxy y así permutar la referencia de los términos sin afectar al significado, pues: "stimulus meaning never suffice to determine even what words are terms, if any, much less which terms are

\footnotetext{
language, we may proceed on that basis to question our informant about sameness of gavagais from occasion to occasion and so conclude that gavagais are rabbits and not stages. But if instead we take 'are stages of the same animal' as translation of that jungle construction, we will conclude from the same subsequent questioning of our informants that gavagai are rabbit stages. Both analytical hypotheses may be presumed posible." (Quine, 1960, p. 72) Como es evidente, la indeterminación de los términos está ligada a la indeterminación de otras partículas, a este fenómeno Quine le llama: “indeterminación correlativa” (véase Quine, 1969, p. 35); en el capítulo II veremos lo que Field tiene que decir al respecto.

${ }^{39}$ Véase: Quine, 1960, p. 53; 1969, p. 45; 1958 p. 7.

${ }^{40}$ De hecho, siguiendo a Hylton (2007, p. 206-8), la IR consiste precisamente en dejar las conexiones oraciones-mundo (las cuales proveen el significado [estimulativo] al lenguaje) y oraciones-oraciones intactas al reinterpretar la ontología. La IR se suma a la ya existente IT.
} 
coextensive [...] (Quine, 1960, p. 70)", y: “divergent interpretations of the words in a sentence can so offset one another as to sustain an identical translation of the sentence as a whole.” (Quine, 1992, p. 50)

Si la tesis de la IR es cierta, el término "gavagai” puede referir a un conejo, a partes-no-separadasde-conejo, o a episodio-temporal-de-conejo, etc. No importa cuántas veces apunte con el dedo el lingüista, la referencia del término en cuestión solo quedaría establecida si determinamos donde empieza y termina un gavagai; la ostensión no nos capacita para establecer las condiciones de individuación de términos (véase Quine, 1969, p. 32).

\subsection{Indeterminación de la referencia y relatividad ontológica.}

La IR puede defenderse de otras formas además de apelar al caso gavagai. Quine introduce las funciones proxy como una forma de reinterpretar la ontología de nuestro lenguaje o teoría de una sola vez sin tener que ir caso por caso. El caso gavagai puede aplicarse ya a nuestro propio lenguaje, de forma que no sabemos a qué refiere nuestro término "conejo". Sin embargo, Quine introduce a las funciones proxy para aclarar y dar plausibilidad a esta hipótesis. Mediante el uso de las funciones proxy, la ontología de nuestro propio lenguaje puede reinterpretarse de formas distintas e igualmente aceptables. Nuestras palabras pueden referir a un objeto $x$, o a un objeto $x^{*}$, o $x^{* *}$, etc.

Entonces, ¿a qué refieren nuestros términos? Al parecer, no tenemos forma de responder a esta pregunta; ${ }^{41}$ no sabemos a qué refieren nuestras propias palabras. ¿No constituye esta consecuencia una posición absurda? A Quine le incomoda este aparente sinsentido y ofrece la OR como solución. Sin embargo, esta última tiene consecuencias indeseables, pues parece implicar la determinación de la referencia, y por tanto, la negación de la IR.

\footnotetext{
${ }^{41}$ Tal vez podríamos recurrir al convecionalismo, pero esta vía no nos interesa ahora. Por el momento, se trata de ver si existe alguna forma naturalista de evitar la IR.
} 


\subsubsection{Funciones proxy.}

Uno de los argumentos clásicos (y que presumiblemente demuestran la IR de forma contúndete [Fogelin, 1996, p. 508]), a favor de la indeterminación de la referencia hace uso de las funciones proxy, las cuales nos permiten reinterpretar la referencia y dejar el significado sin cambios. (Quine, 1981, p. 19)

La primera mención de una función proxy se hace en Ontological reduction and the World of Numbers (Quine, 1964, p. 204), donde se intenta reducir una ontología a otra. ${ }^{42}$ Según el razonamiento ahí planteado, dadas dos teorías $T$ y $T^{\prime}$, se introduce una función, ya sea en la notación de las teorías bajo estudio o en una metateoría que admita como argumentos todos los objetos del universo de $T$ y tome valores en el universo de $T^{\prime}$ (los objetos de $T$ serían el input de la función y los valores resultantes u output serían los objetos de $T^{\prime}$ ). Un ejemplo de la reducción ontológica, siguiendo a Frege, sería la reducción de los números a clases. Al aplicar la función proxy al número 5 obtenemos como valor la clase de todas las clases compuestas por cinco miembros $K$. Así, en general, $K$ se describe como la clase de todas las clases con $x$-miembros. Ahora bien, si "this can be done, with preservation of truth values of closed sentences, we may well speak of reduction of natural numbers”. Entonces la condición básica para reducir una ontología a otra sería usar una función proxy que conserve los valores de verdad de oraciones.

Este mismo procedimiento sirve para reinterpretar la ontología. ${ }^{43}$ Sólo necesitamos de una función proxy que conserve valores de verdad (y las condiciones de verdad o disposiciones al comportamiento verbal dadas ciertas condiciones estimulativas) y las relaciones inferenciales entre oraciones (Reynolds, 1994). Así, la indeterminación de la referencia: “occurs even if we suppose all problems about truth to be settled -even if we suppose that we possess a theory of the world whose

\footnotetext{
${ }^{42}$ Quine (1981, p. 19) cree que las reducciones ontológicas (reinterpretación reductiva de números a clases, de objetos físicos a espaciotiempo, de espacio-tiempo a cuádruples de números, de mente-cuerpo a estados físicos, etc.) son gratificantes porque reducen las cosas a un solo dominio ontológico. En este sentido, el uso de las funciones proxy responde a un motivo específico. En el caso de la IR el empleo de proxys no depende de una razón o motivo específico.

${ }^{43}$ Una interpretación consiste en la "complete assignment of extensions to the singular terms and predicates of L.” (Nimtz, 2005, p. 2)
} 
complete truth is not in doubt. Such a completely true theory is, after all, a body of true sentences." (Hylton, 2004, p. 134) Que referencia haya no es importante para la verdad o la evidencia. El input de nuestro lenguaje está dado por oraciones ocasionales; el output por oraciones sobre el mundo. Los objetos son meros índices que podemos permutar: "supplant them as we please as long as the sentence-tosentence structure is preserved" (Quine, 1981, p. 20), y: "What particular objects there may be is indifferent to the truth of observation sentences, indifferent to the support they lend to the theoretical sentences, indifferent to the success of the theory in its predictions.” (Quine, 1992, p. 31)

Las funciones proxy refuerzan la plausibilidad de la $\mathrm{IR},{ }^{44}$ pues dada una interpretación $N$ para nuestro lenguaje, la función permite generar muchas más interpretaciones $-\mathrm{o}$ asignaciones de referentes a los términos del lenguaje- $-N^{*}, N^{* *}, N^{* * *}$, etc. Asimismo, las funciones proxy dejan las relaciones inferenciales entre oraciones, y los valores de verdad de estas últimas sin alterar. La evidencia es prácticamente neutral respecto a la elección de una ontología específica. La función de la ontología en un teoría científica estaría dada primordialmente, al parecer, por contribuciones pragmáticas: "I conclude from [the indeterminacy of reference as shown by proxy functions] that what matters for any object, concrete or abstract, is not what they are but what they contribute to our overall theory of the world as neutral nodes in its logical structure" (Quine, 1995b, 74-5; véase también Gibson, 1998b, p. 681), y: "[...] the role of reification in the theory of scientific evidence $[\ldots]$ is a mere positing of neutral nodes in the structure of scientific theory, as shown by the proxy functions." (Quine, 1983, p. 318)

Hace un momento se hablaba de la IR como consecuencia de la IT del aparato individuativo. Ahora, si bien el Quine de Word and Object aparentemente circunscribía el problema de la IR a la traducción de un lenguaje nativo, en Ontological Relativity explicita que la IR se extiende al propio

\footnotetext{
${ }^{44}$ De hecho, según (Glock, p. 220), el uso de las funciones proxy para apoyar la tesis de la IR conlleva otras ventajas: 1) nos permiten realizar, de forma coordinada, una serie de reinterpretaciones a la vez (en lugar de ir caso por caso); 2) no alteran la categoría sintáctica de los términos (de término general, a término singular abstracto, por ejemplo); 3) no cambian la cardinalidad de las extensiones de los términos generales, al contrario de lo que sucede en: "conejo" y "partes-no-separadas-de-conejo".
} 
lenguaje. La IR no sólo ocurre en el contexto de la traducción radical sino también en la traducción homofónica (la traducción homofónica traduce series de palabras a ellas mismas): ${ }^{45}$ “On deeper reflection, radical translation begins at home." (1969, p. 46); “we can systematically reconstrue our neighbor's apparent references to rabbits as really references to rabbit stages [...] In short, we can reproduce the inscrutability of reference at home." (Quine, 1969, p. 47)

Si se toma en serio la IR, la ontología de nuestro propio lenguaje está indeterminada. Ello no debe ser causa de sorpresa, pues, como hemos visto, los hechos que sustentan la traducción no alcanzan para determinar significado ni referencia. Si esto es así ¿acaso tiene sentido preguntar cuál es la referencia real de tal o cual término? ¡Claro que no! Pues una vez que se han agotado los hechos relevantes (determinantes), simplemente "there is no fact of the matter." (Quine, 1969, p. 47) ${ }^{46}$ Esta falta de un fact of the matter impide la determinación de la traducción de oraciones. (Hylton, 2007, p. 204)

Ciertamente la concepción misma de la IR en nuestro propio lenguaje parece una posición disparatada. Precisamente a esta conclusión llega Quine (1969, pp. 47-8). Aparentemente uno no sabe si se refiere a conejos, partes-no-separadas-de-conejo, etc., pero ¿no parece esto absurdo? Es en este punto cuando este filósofo (1969, p. 48) propone como solución la OR: "Fair enough; reference is nonsense except relative to a coordinate system. In this principle of relativity lies the resolution of our quandary"; "The shock subsides, however, when we reflect on a homely example or two. Thus think of a body in the scientific framework of space and time.” (1995, p. 470)

\footnotetext{
45 "He ahí un conejo" se traduce como "He ahí un conejo". La traducción homofónica es esencial para aprender el propio lenguaje (mediante la imitación y la retroalimentación). No obstante, una vez que consideramos nuestro lenguaje desde una perspectiva teórica la IR persiste. ${ }^{46}$ De hecho, como veremos más abajo, la solución a al IR vendría a ser la OR. Presumiblemente, Quine cree que si los hechos asequibles al lingüista no alcanzan para determinar la referencia, entonces apelar a la relativización de la referencia a un lenguaje de fondo resolvería la dificultad: "what my argument from proxy functions shows is that there is no fact of the matter except relative to a target language and a manual of translation." (Quine 1986d, p. 429) Aparentemente el fact of the matter si existe después de todo siempre y cuando relativizemos nuestros términos; sin embargo, si una vez hecha la relativización, persiste la IR (como Quine parece creer), ello se debe a la carencia genuina de un fact of the matter.
} 


\subsubsection{La relativización de la ontología como solución al problema de la indeterminación.}

Presumiblemente, nuestro aparato referencial: nuestro lenguaje de fondo o teoría de fondo, nos permite distinguir entre conejos, partes-no-separadas-de-conejo... Relativa a este aparato, la referencia queda determinada. ${ }^{47} \mathrm{El}$ aparato individuativo juega la función de lo que en la física se denomina "marco de referencia" o "sistema coordenado", a través de éste podemos determinar la ubicación o velocidad de un objeto. ${ }^{48}$ Así, la referencia queda determinada, aunque sólo en un sentido relativo, no absoluto. Preguntar por la referencia en un sentido absoluto sería análogo a preguntar por la posición absoluta, o la velocidad absoluta, ambas preguntas absurdas.

Así como la referencia se determina en relación a un lenguaje de fondo, cualquier pregunta sobre el lenguaje mismo se resuelve en relación a otro lenguaje más amplio. Lo mismo sucede en la física. La posición de un sistema coordenado se determina en relación a un sistema más amplio. En teoría, el regreso puede continuar indefinidamente, pero en la práctica termina cuando tomamos nuestro lenguaje al pie de la letra o cuando apuntamos con el dedo según sea el caso. Sin embargo, esto no significa que tomando el lenguaje de forma literal se solucione la IR:

To take the words of our language "at face value" is not to attribute special meanings to them, meanings which escape the indeterminacy argument in some special way. It is simply using them, and not asking for an explanation of their meaning in other terms. (Hylton, 2007, p. 213)

Independientemente de la práctica, debemos relativizar nuestros términos a un lenguaje dado. Debemos dar cuenta de los referentes en relación al lenguaje de fondo. Necesitamos "[...] a relational theory of what the objects of theories are. What makes sense is to say not what the objects of a theory

\footnotetext{
47 Según Quine: "Bodies [...] are distinguished in a relativistic way, by their roles relative to one another and to the rest on ontology." (1992, p. 33; énfasis añadido)

${ }^{48}$ Podríamos visualizar a la OR desde otra perspectiva, según la cual el rol de los términos en el lenguaje determina su contenido, por ejemplo en el caso de los predicados: "The relevant predicates -"number," "set," "body," or whatever- would be distinguished from one another in the background theory by the roles thy play in the laws of that theory." (Quine, 1969, p. 60)
} 
are, absolutely speaking, but how one theory of objects is interpretable or reinterpretable in another." (Quine, 1969, p. 50) ${ }^{49}$ Para este filósofo no tiene sentido hablar de ontología en un sentido absoluto, pues esta perspectiva absoluta implica un tipo de circularidad (implica y/o necesita ya de una relativización): "What makes ontological questions meaningless when taken absolutely is not universality but circularity. A question of the form "What is an F?" can be answered only by recourse to a further term: "An $F$ is a G." The answer makes only relative sense: sense relative to the uncritical acceptance of “G." (Quine, 1969, p. 53; véase también p. 54) Me atrevo a afirmar que con la expresion "the uncritical acceptance of ' $G$ '”, el autor apunta a la aceptación al pie de la letra de nuestro lenguaje.

Para Quine (1969), la OR corresponde a la tesis según la cual: "it makes no sense to say what the objects of a theory are, beyond saying how to interpret that theory in another." Las oraciones y variables de nuestro lenguaje o teoría se interpretan pero sólo en un sentido relativo, en relación a nuestro propio lenguaje (home language); es decir, la asignación de objetos a las variables, extensiones a los predicados, y valores de verdad a las oraciones es posible porque ya existe un lenguaje doméstico en relación al cual podemos establecer la interpretación (que por naturaleza es relativa y no absoluta). Así, Quine (1969, p. 51) acepta la determinación de la referencia pero únicamente en un sentido relativo: “we do fully interpret the theory, relative to our own words and relative to our overall home theory which lies behind them." Sin embargo, parece entreverse alguna clase de inconsistencia aquí, pues por un lado se acepta la IR, pero por otro se consiente la determinación relativa de la referencia. Cabe mencionar que Quine parece no haber visto ninguna tensión en este punto: "I argued ontological relativity on the strenght of proxy functions.” (Quine, 1986d) Tampoco en su respuesta a Paul Roth (1986a, p. 459): “The inscrutability of

\footnotetext{
${ }^{49}$ Ciertamente, la ontología está indeterminada aun cuando la teoría relacional nos permita señalar todas las propiedades de cierto objeto. En otras palabras, la IR persiste tomemos o no en cuenta las propiedades del objeto presumiblemente hechas manifiestas por la relativización.
} 
reference implies ontological relativity. I have no quarrel here, but I do not see what difference there is between the two." (Véase también, Gibson en Schilpp, p. 680)

Sin embargo, como hemos mencionado arriba, Quine concibe la OR como solución a la IR, ¿porque entonces afirma que no ve la diferencia entre IR y OR, entre el problema y su solución, entre una tesis de indeterminación y una de determinación? Quizás Quine se refiere a la indeterminación de la referencia como "IR" y "OR" indistintamente (véase Hylton, 2004, pp. 128-9) No obstante, podemos distinguir, prima facie, dos tesis distintas, ${ }^{50}$ las cuales seguiremos llamando como se ha venido haciendo. El mismo Quine (1992, p. 51) no parece haber hecho distinción alguna: "Kindly readers have sought a technical distinction between my phrases 'inscrutability of reference' and 'ontological relativity' that was never clear in my own mind". ${ }^{51}$ Si hacemos caso a las interpretaciones de Field y de Davidson, Quine pierde el piso en este punto; quizás sin darse cuenta está proponiendo algo inconsistente. En los siguientes capítulos examinaremos las críticas de estos filósofos en más detalle, y veremos una especie de OR que, compatible con la IR, evite esta notoria falla en el sistema filosófico quineano. Mientras tanto, veamos un poco más sobre la OR tal como la concebía Quine.

Si no tomamos en cuenta la parte no-lógica de nuestro lenguaje (términos singulares y generales, predicados, nombres, etc.,), nos quedamos con la parte formal (funciones de verdad, la identidad, cuantificadores, etc.). Ahora bien, a esta estructura lingüística puramente formal podemos complementarla con vocabulario no lógico a fin de que las oraciones adquieran valor de verdad. Contamos con diversas opciones para tales valores de verdad, cada una de las cuales recibe el nombre de modelo. Como ya vimos, los hechos estimulativos no determinan completamente como interpretar la teoría, es decir, que referentes asignarle. ¿Qué opción nos queda? La única alternativa apropiada parece corresponder a la OR: "Paraphrase in some antecedently vocabulary, then, is our only recourse; and such

\footnotetext{
${ }^{50}$ Greenlee también acusa a Quine de confundir las tesis: "Relativity of scrutiny is not the same as impossibility of scrutinity, or inscrutability. Quine confuses the two”. (1973, p.578)

${ }^{51}$ Expresiones similares pueden encontrarse en Quine, 1970, p. 183; 1994b, p. 458.
} 
is ontological relativity." (Quine, 1969, p. 54) ${ }^{52}$ Sin embargo, la OR no resuelve el problema; sigue existiendo indeterminación. No obstante, la OR nos garantiza, según nuestro autor, un tipo particular de determinación, aunque no absoluta. ¿Puede existir, entonces, una determinación parcial? Quine no es muy claro sobre el asunto; más bien, sus tesis parecen llevarnos a conflictos intrincados, pues alguien podría argumentar la aparente inconsistencia entre su relativismo ontológico y su realismo (véase, Vuillemin, y la réplica de Quine 1986b p.622; también la réplica a Lee p. 316).

La OR puede implicar más de una relativización. La relativización puede conformarse de dos componentes: primero, la relativización, de una teoría $T$, a un lenguaje de fondo $L$, y, segundo, la relativización a un manual de traducción sobre como traducir la teoría $T$ en $L$. Asimismo, si quisiéramos establecer o determinar la ontología de la teoría de fondo necesitaríamos recurrir, a su vez, a otra teoría de fondo (punto ya mencionado arriba) de forma que la primera sería una teoría subordinada a la segunda. Pero esta forma de proceder no implica, presumiblemente (siempre), un genuino regreso al infinito. Por ejemplo, en el caso de la clarificación del rango de las variables de una teoría o de la denotación de sus términos, se toma la referencialidad de la cuantificación como dada (se toma el lenguaje al pie de la letra), puede tomarse a la teoría objeto misma como la teoría de fondo. ${ }^{53}$ Por otro lado, los términos de una teoría $T$ pueden relativizarse a $T$ misma: "this is the case when some terms are clarified by definition on the basis of other terms of the same language." (Quine, 1969, p. 61) Ahora bien, por otro lado y a forma de aclaración: "such talk of subordinate theories and their ontologies is meaningful, but only relative to the background theory with its own primitively adopted and ultimately inscrutable ontology." (Quine, 1969, p. 51) Es decir, siempre después de una relativización persiste la IR.

\footnotetext{
${ }^{52}$ Field criticará esta posición bajo el supuesto de que nos hace perder el mundo, lo objetivo, y basa la referencia en el mero lenguaje.

${ }^{53}$ Esto debería responder - como veremos más adelante- a las preocupaciones de Davidson sobre el regreso infinito. Sin embargo, el problema parece más profundo; esta solución parcial quineana al regreso infinito corresponde sólo a una manifestación de la suposición quineana errónea de que la referencia está determinada en algún sentido. Así, Quine reconoce un límite al regreso una vez que se postula cierta determinación referencial.
} 
La idea de relativización afecta también a la noción de identidad misma, pues la identificación de algo implica conocer que lo distingue de otras cosas. Como hemos visto para Quine el lenguaje corresponde a un conjunto de oraciones interrelacionadas. De este holismo, derivó las bases de la OR y la consecuente relativización de la identidad. Intentemos aclarar un poco más la cuestión. Supongamos (basándonos en el ejemplo quinenano sobre una teoría económica [1969, p. 55] que contamos con una teoría biológica, cuyo universo abarca animales, y sus predicados no distinguen entre animales homeotermos y animales en general. Si es así, entonces no podemos diferenciar a los animales por su tamaño, su número de extremidades, su hábitat, etc., pues la teoría carece de los recursos expresivos necesarios para realizar esas distinciones. Sólo podemos hablar distintamente de animales homeotermos. La noción de identidad (decir que tal o cual es un animal homeotermo [pues decir que una cosa es implica decir de esa misma cosa que es idéntica a sí misma]) está limitada por su relación con todas las demás expresiones que conforman la teoría. Si quisiéramos hablar de tamaños, u otras características y su identificación, necesitamos expandir el lenguaje. Como veremos más abajo, Field considera la identidad como un término base al cual están ligados otros secundarios. Si la expresión base sufre indeterminación, lo mismo sucederá con los vocablos ligados a ella. Sin embargo, el punto de Quine es otro: la referencia sólo tiene sentido si la relativizamos, y ello implica cierto tipo de determinación de la misma.

Hemos visto como las funciones proxy sirven a la causa de la IR, y como la indeterminación de significado y de referencia afectan incluso nuestro propio lenguaje. Por último, hemos seguido a Quine en su intento por evitar este aparente absurdo (no saber a qué refieren los términos de nuestro propio lenguaje) mediante la OR. Sin embargo, también parece surgir un problema de inconsistencia entre las tesis IR y OR. No es de sorprender que incluso el mismo Quine parece no haber tenido muy claro él mismo la conexión entre ellas. En los siguientes capítulos, abordaremos esta tensión entre las doctrinas y la solución ofrecida por Davidson. 


\section{CAPÍTULO II}

\section{LA CRÍTICA DE FIELD Y LA TEORÍA CAUSAL DE LA REFERENCIA}

En este capítulo se expone y apoya la crítica de Field a la solución quineana (OR) para la IR. También se presenta la teoría causal del mismo autor y como ésta podría resolver el absurdo vislumbrado por Quine, además de proveer de una noción de IR más adecuada. ${ }^{54}$ En la propuesta de Field IR y teoría casual se encuentran íntimamente asociadas. Su conjunción da cuenta, presumiblemente, de la IR en el cambio de las teorías, y ofrece una versión fisicalista aceptable de la noción de referencia.

En diversos artículos, Field señala la tensión (la ininteligibilidad de su conjunción) entre la IR y la OR quineanas. Es cierto que habría quien no esté de acuerdo con el diagnostico de Field (véase Roth, 1986). Sin embargo, como hemos visto en el capítulo anterior (y veremos a continuación), contamos con buenas razones para pensar que Quine es presa de una inconsistencia y que no hizo nada para subsanar este problema. Aún más, Quine no creía necesario ofrecer una solución, pues él mismo no veía ningún problema. Ahora, gracias a la obra de Field, podemos indicar la dificultad y embarcarnos en la búsqueda de una solución a la misma.

La solución de Field propone, a fin de cuentas, una forma de IR. Una nueva forma de concebir la IR, la cual, entre otras cosas, parece evitar el absurdo de que no sabemos a qué nos referimos señalando

\footnotetext{
${ }^{54}$ No obstante, en el capítulo III se muestran sus deficiencias y porque no constituye una buena alternativa al naturalismo quineano.
} 
la conexión causal determinada entre palabras y sus referentes parciales. A pesar de todo, al final del capítulo se pronostica ya que ninguna de las tesis ofrecidas por Field resuelve el problema planteado por la IR. En primer lugar, la noción de referencia parcial presupone una cierta determinación de la referencia que bien puede ponerse en duda si se acepta la tesis de la IR, como Field lo hace. En segundo lugar las supuestas conexiones causales entre palabras y objetos estarían indeterminadas en el mejor de los casos. Estos problemas se abordarán con más detalle en el capítulo III. Mientras tanto, el objetivo principal de este capítulo consiste en mostrar que existe un problema de inconsistencia en el sistema filosófico quineano; que existe la alternativa de Field y constituye una buena opción naturalista y atractiva que probablemente resolvería la IR, y, sino, al menos echaría luz sobre el problema.

\subsection{Crítica a Quine: Imposibilidad de derivar la relatividad ontológica $(\mathrm{OR})$ de la indeterminación de la referencia (IR).}

Field y Quine concuerdan en que la referencia está indeterminada, pero difieren en su concepción sobre la naturaleza de la misma. Field acepta la IR pero sólo para algunos términos (particularmente los científicos). Pero más importante aún, para Field la IR significa referencia parcial determinada a por lo menos dos objetos.

Ahora bien, la IR tal como Quine la concibe no implica determinación completa alguna (mucho menos del tipo vislumbrado por Field), y si la implica, ésta debe convivir con la IR (como hemos visto Quine mantiene IR y OR al mismo tiempo). Quine presupone algún grado de indeterminación aun cuando hemos relativizado la ontología a un manual de traducción o una teoría. Por otro lado, la OR conlleva aceptar de antemano la determinación completa de la referencia del lenguaje de fondo (a fin de poder

llevar a cabo la relativización). Así, la OR supone la no existencia de IR en el lenguaje de fondo, pero ¡Quine ya había pronosticado la existencia de IR en ese mismo lenguaje! 


\subsubsection{Incompatibilidad entre OR e IR.}

Field interpreta la tesis de la relatividad ontológica quineana como afirmando la falta de sentido del discurso que concibe a los términos, de una teoría o lenguaje, denotando en un sentido absoluto. ${ }^{55}$ Así, sólo tendría sentido hablar de la denotación y significación de los términos si restringimos el sentido de dichas nociones a lo facilitado por la interpretación o reinterpretación de una teoría en otra. Para Field (según su interpretación de Quine), la OR consiste en: "The view that it makes no sense to speak of "absolute" correspondence relations between words and extralinguistic objects, and that what does make sense is to say how one language or theory is translatable and retranslatable into another." (1974, p. 206)

Sin embargo, según Field, la idea misma de una relativización de la ontología (en el sentido quineano) obstaculiza una interpretación fisicalista de la referencia, de toda interpretación no-semántica de cualesquiera conceptos semánticos y de una teoría correspondentista de la verdad del tipo Tarski. ${ }^{56}$ De esta manera, Quine, quien se proclama partidario del fisicalismo (en un sentido general) y aboga por una teoría de la verdad tarskiana ${ }^{57}$ parece irrumpir contra sus propias asunciones al sugerir la reinterpretación de una teoría en otra. Eso implica, según Field, una correspondencia entre palabras y palabras, y no entre palabras y mundo; pero, presumiblemente, Tarski no pensaba en este tipo de correspondencia, ni el fisicalismo (que el mismo Quine dice apoyar) parece compatible con tal posición.

Así, el fisicalismo implica una correspondencia entre palabras y objetos físicos; la teoría tarskiana, entre lenguaje y mundo. La OR implica, por otro lado, una correspondencia entre palabras y palabras; entre lenguaje y lenguaje. Un término refiere sólo en relación a un lenguaje (a un conjunto de otros términos y expresiones lingüísticas). Pero ¿esta OR realmente implica un abandono del fisicalismo

\footnotetext{
${ }^{55}$ Interpretación muy acorde a las intenciones del propio Quine, y acertada, si lo expuesto en el primer capítulo es correcto.

${ }^{56}$ Que por otro lado Quine dice favorecer.

${ }^{57}$ la cual pretende rescatar la noción de verdad-correspondentista aristotélica.
} 
y de la teoría de verdad tarskiana? No necesariamente. En el sistema filosófico quineano la ontología no está determinada o conformada meramente por el lenguaje. No obstante, Field busca una conexión más robusta entre lenguaje y mundo donde los referentes de los términos existen independientemente del lenguaje. Sin embargo, esta discusión va más allá de los objetivos del presente trabajo, por lo cual, en lo sucesivo, sólo la abordaremos tangencialmente.

La OR también parece implicar una confusión entre uso y mención (Field, 1974, p. 206), pues explica la relatividad como sigue:

(U) El término $T$ refiere al objeto $x$ en relación a un manual $M$ sii $M$ traduce $T$ como “ $x$ ".

Sin embargo, este problema puede resolverse (o al menos así lo cree Field), si explicamos la relatividad de la siguiente manera:

(V) El término T refiere al objeto $x$ en relación a un manual M sii M traduce T en algún término que refiere a $x$.

Si esta es una buena respuesta o no al problema no será discutido en este trabajo, pues creo con Field (1974, p. 206) que la dificultad esencial radica en que la formulación de la OR presupone la negación de la IR.

La inconsistencia entre la OR y una teoría de la verdad correspondentista y la aparente confusión entre uso y mención no representan los únicos problemas de la tesis relativista de Quine. ${ }^{58}$ El verdadero problema yace en la inferencia IR $\rightarrow$ OR. Ciertamente Quine concibe la OR como solución al problema introducido por la IR, de ahí que Field interprete ese movimiento de la forma ya mencionada. Pero, ¿realmente se sigue la OR de la IR? Field piensa que no, más bien, él cree que la aceptación de la OR nos lleva a la negación de la IR. Quine busca en todo momento probar la existencia de IR y

\footnotetext{
${ }^{58}$ Más adelante veremos cómo Field desecha la OR y muestra una forma de conciliar IR y la teoría correspondentista de la verdad vía la noción de determinación parcial de la referencia.
} 
simultáneamente adopta la OR. Pero el resultado de esta adopción consiste en la determinación de la referencia, o sea, la negación de la IR. Quine mantiene, cayendo en una inconsistencia, ambas tesis al mismo tiempo IR y OR. El punto de Field puede establecerse de la siguiente manera:

(F) Es incoherente mantener IR y OR al mismo tiempo, pues:
a) $\mathrm{IR} \rightarrow \neg \mathrm{OR}$
b) $\mathrm{OR} \rightarrow \neg \mathrm{IR}^{59}$

¿A qué se debe esta presunta incoherencia? La dificultad está en que Quine define la noción de referencia, "Only in terms of an unrelativized notion of signification applied to our own language (the language into which we translate). So it seems that we have to understand this unrelativized notion before we can understand the relativized notion employed." (Field, 1974, p. 206) En definitiva, la IR no puede fungir como argumento a favor de la OR (Field 1974, p. 200).

Así, Quine yerra al presuponer la comprensión de terminología que de otro modo debería ser incomprensible, más aún, la OR sólo tiene sentido si se presupone una noción determinada de referencia Así, la idea de una referencia relativizada carece de sentido, pues hablar de determinación implica una noción absoluta. Lo anterior estaría bien si Quine no defendiera al mismo tiempo la IR. El problema reside en que para dar sentido a la noción de OR debemos dar por sentada la determinación de la referencia, y así, Quine niega lo que en un principio había creído demostrado, a saber: la IR. Por consiguiente la relativización de la ontología requiere forzosamente la aceptación de la determinación de la referencia de los términos de un lenguaje $L$.

Como ya mencionábamos en el primer capítulo, la analogía quineana entre la OR y el sistema espacial coordenado falla en su intento de definir "el término $T 1$ denota $x$ relativo al término $T 2$; al

\footnotetext{
${ }^{59}$ a) y b) son lógicamente equivalentes. Se presentan ambas por motivos didácticos y de claridad.
} 
lenguaje de fondo" $" 60$ apelando a las relaciones lingüísticas entre $T 1$ y $T 2$ (o sea: tratar de definir la noción de referencia relativizándola). Según Field, si bien es cierto que " $x$ tiene una velocidad $v$ relativa a y" se define en términos de las relaciones espaciales entre $x$ y y, no es así en semántica o lingüística (usando la terminología de Field). La dificultad fundamental reside en nuestra incapacidad de definir o dar sentido a la oración, “el término $T 1$ denota $x$ relativo a $T 2$ " (o la noción de referencia relativizada) sin apelar a lo no deseado: la determinación de la referencia, ya sea del término $T 1$ o $T 2$. En palabras de Field:

In fact (and this is my argument in the text), there is no hope in defining this last predicate at all unless we can establish a relation between either $T 1$ or $T 2$ on the one hand, and $x$ (and no object other than $x$ ) on the other. But that is just what the indeterminacy thesis precludes us from doing. (1974, p. 208)

Nos encontramos pues con una dificultad interna en el sistema filosófico quineano. ${ }^{61}$ Field tratará de dar una solución y Davidson ofrecerá otra ¿Alguna de ellas resuelve el problema? Aunque ambas tienen sus defectos, creo que la propuesta de Davidson resuelve el problema de forma satisfactoria, sobre todo porque no desecha estrictamente ninguna tesis quineana.

\subsubsection{Convencionalismo, Instrumentalismo y relatividad ontológica.}

Field rechaza la OR como solución o consecuencia de la IR, pero, al final, propone una versión de IR. Este asunto lo abordaremos en las siguientes secciones. Mientras tanto, veamos algunas distinciones importantes entre la IR, la OR y otras tesis emparentadas, a fin de establecer el marco teórico a partir del cual Field concibe la IR y la OR quineanas, así como su solución a la IR (y su rechazo de la OR) basada en una teoría de la referencia causal (la cual se encuentra ligada a la noción de "referencia parcial").

\footnotetext{
${ }^{60}$ Field cree que la dependencia de la referencia de un término al lenguaje de fondo puede entenderse como la dependencia de un término a otros términos.

${ }^{61}$ Roth (1986, p. 450-51) no cree que exista esta inconsistencia, sin embargo su respuesta sólo tendría efecto si presuponemos la distinción IR en la práctica/ IR a nivel la teoría, pero es dudoso o, al menos, objeto de diputa que tal distinción sirva para resolver el problema.
} 
Aparentemente existe una afinidad importante entre la IR y el convencionalismo; sin embargo, Field trata de exponer la gran diferencia entre ambas tesis; la verdad y trivialidad del convencionalismo, y la falsedad de la IR. Asimismo señala las similitudes -en tanto ambas conllevan algún tipo de arbitrariedad- y diferencias entre el convencionalismo y la OR.

Presumiblemente (siguiendo a Field) las funciones proxy sirven para apoyar el convencionalismo, pues nos dejan con diversos esquemas de referencia todos igualmente adecuados y no dejan otra alternativa que elegir sólo uno de ellos si queremos evitar la IR. Simplemente no tenemos forma de decidir entre esquemas que no sea mediante una decisión arbitraria. ${ }^{62}$ Frente a este problema contamos por lo menos con dos formas de evitar la indeterminación:

(a) El convencionalismo; ${ }^{63}$

(b) La OR.

El convencionalismo resuelve el problema de la diversidad de esquemas de referencia igualmente adecuados mediante la selección de sólo uno de ellos. La OR ofrece una respuesta similar (según Field) pues la relativización de la referencia al esquema 1 o al esquema 2 conlleva la elección arbitraria de uno de ellos. ${ }^{64}$ En este sentido, Quine responde a la IR (aunque no de forma directa. De manera directa

\footnotetext{
${ }^{62}$ la IR puede entenderse como la existencia de diversos esquemas referenciales, interpretaciones o modelos diferentes pero todos adecuados dados todos los hechos relevantes para la determinación del contenido semántico del lenguaje.

${ }^{63}$ Field (1975) menciona varias formas posibles de evitar el convencionalismo mediante condiciones de adecuación: determinación razonable de las condiciones de verdad de las oraciones del lenguaje $L$ (esto conlleva un tratamiento tarskiano de nuestro lenguaje), simplicidad; conformidad al uso habitual de los términos; conformidad con el modelo desentrecomillador de verdad (referencia en este caso), etc. A fin de cuentas ninguno parece satisfactorio y de ahí Field concluye la verdad del convencionalismo. Apelar a la simplicidad no evitaría que una reinterpretación fuera convencional; las condiciones de verdad serían las mismas para la ontología normal y su reinterpretación; el uso habitual reflejaría simplemente nuestro condicionamiento, nuestra convención implícita para usar un esquema de referencia en particular; podríamos haber sido condicionados en el uso de una ontología permutada, etc. (Desentrecomillar no resolvería la dificultad, porque siempre existiría un esquema desentrecomillador disponible aplicable a la ontología reinterpretada, así: "[...] no considerations about diquotation schemas succed in undercutting the thesis that the choice of a reference scheme for our own language is conventional." (Field, 1975, p. 382)

${ }^{64}$ Field emplea los términos "arbitrario" y "convencional” más o menos de forma indistinta.
} 
responde al regreso al infinito) mediante una elección arbitraria de un esquema de referencia particular. La diferencia entre el convencionalismo y la OR residiría meramente en la motivación pragmática detrás de la segunda. Aunque el convencionalista está en su derecho de realizar la elección según principios pragmáticos, no está por ello comprometido a hacerlo. En cambio, la OR tal como Quine la entiende se realiza en función de aquellos; de ahí que Field (1974) conciba a la OR como una tesis instrumentalista, más bien que convencionalista, sobre la referencia.

Si adoptamos este enfoque, debemos concluir con Field que la OR implica una serie de decisiones arbitrarias. ${ }^{65}$ Supongamos, pues, que el término "masa" tal como lo usaba Newton denota parcialmente dos referentes: masa relativista y masa en reposo (más adelante se explicará en términos generales en que consiste la denotación parcial y conceptos asociados). Quine pretende evitar este concepto de denotación parcial estableciendo un solo referente para el término "masa", pero si nos tomamos en serio su idea según la cual no existe un fact of the matter que permita decidir entre las alternativas, entonces la elección sería meramente arbitraria. ${ }^{66}$ Así, por cada denotación parcial (masa relativista y masa en reposo) existe una estructura que asigna esa misma denotación al término, y no contamos con los medios para decidir entre: a) "masa" refiere a masa relativista en relación a un esquema 1, o bien b) "masa" refiere a masa en reposo en relación a un esquema 2. La pregunta para Quine es: ¿a qué esquema debemos relativizar el término "masa"? Presumiblemente, Quine no ofrece una respuesta satisfactoria a esta pregunta, la elección entre esquemas - la relativización- parece más bien arbitraria. De ahí que Field

\footnotetext{
${ }^{65}$ Al menos parcialmente. Field mismo (1974), etiqueta a la tesis quineana como: "el enfoque de la elección arbitraria, y esto parece justificarse, presumiblemente, pues cuando hablamos de la ontología de nuestro lenguaje, Quine afirma: "[...] the very notion of object, concrete or abstract, is of our own making [...] This conventionalist view of ontology appeals, I expect, to Henri Lauener.” (1995a, p. 471); "A lesson of proxy functions is that our ontology, like grammar, is part of our own conceptual contribution to our theory of the world." (Quine 1992a, p. 36; énfasis mío); "It is occasion sentences, not terms, that are to be seen as conditioned to stimulations. Even our primordial objects, bodies, are already theoretical -most conspicuously so when we look to their individuation over time.” (Quine 1981a, p. 20); “we must conclude that objects of any sort figure only as neutral nodes in the structure of scientific theory, so far as empirical evidence is concerned. We can arbitrarily change the values of our variables [...].” (1995a, p. 469)

${ }^{66}$ El que sea pragmática no implica que la elección deje de ser un tanto arbitraria.
} 
afirme: "[...] the second important respect in which my view differs from Quine's is that I do not see indeterminacy as showing any arbitrariness in semantic theory.” (Field, 1974, p. 223)

Con el fin de alejarse de las tesis no-realistas o tesis antirealistas (el convencionalismo y la OR o el instrumentalismo ${ }^{67}$ ), Field indica la importancia de contar con una teoría de la referencia, a saber: una teoría que explique nociones semánticas en términos no-semánticos; particularmente fisicalistas, basados en la noción de causalidad. La teoría de la referencia propuesta consistiría básicamente en un conjunto de bicondicionales de la siguiente forma: $\forall x \quad \forall y[x$ denota $y$ sii $D(x, y)]$ y $\forall x \quad \forall y[x$ es verdadero de y sii $T(x, y)$ ] donde $D(x, y)$ representa la contraparte no-semántica (reducing formula) de la oración “ $x$ denota $y$ ", y lo mismo para $T(x, y)$ respecto de la oración " $x$ es verdadero de $y$ ". Ahora bien, la teoría de la referencia debe acomodarse al esquema de referencia para que éste sea adecuado. Así, Field intenta ir más allá del lenguaje, hacia el mundo. La teoría de la referencia nos indica cual debe ser la relación entre el término y el objeto, si el esquema asigna al término un objeto que se acopla a los requerimientos de la teoría, entonces el esquema resulta adecuado.

Según Field, un esquema de referencia debe cumplir dos requisitos para ser adecuado: a) formar parte de una teoría de la verdad tarskiana que genere condiciones de verdad razonables para las oraciones $^{68}$, y b) debe existir una teoría de la referencia que se acople al esquema en cuestión (el dominio de la teoría de la referencia incluiría todos los términos contenidos en el esquema de referencia correspondiente). En otras palabras, debe existir una teoría de la referencia que explique de forma naturalista (en términos no-semánticos) los términos semánticos empleados en el esquema de

\footnotetext{
${ }^{67}$ Vuillemin (1986) también creía que el instrumentalismo, potencial al menos, en la obra quineana presentaba problemas a la posición realista de Quine. Sin embargo, Quine (1958, p. 7) reconoce, además de principios pragmáticos, cierta influencia de la experiencia en la determinación de la referencia. Salomon (1990) señala la adopción de la teoría de la verdad de Tarski por parte de Quine como una forma de librarse, hasta cierto punto, de consecuencias y acusaciones antirrealistas.

${ }^{68}$ Para este propósito, uno necesita el esquema de referencia más lo que Field llama "un sistema de reglas proyectivas" a fin de generar las condiciones de verdad de las oraciones del lenguaje $L$. Los detalles se encuentran en Field, 1975, p. 377.
} 
referencia. ${ }^{69}$ Ahora bien, según Field, la tesis de la IR no cumple con ningún requisito, en tanto implica la imposibilidad de una teoría de la referencia (contra b), e imposibilita la discriminación entre conejos, partes-no-separadas-de-conejo, etc., cuando la teoría de Tarski, en tanto empleamos un esquema T normal o no permutado, no hace tal discriminación (véase Field, 1975 p. 400). ${ }^{70}$ Así, la IR no daría pie a la $\mathrm{OR}$, o a alguna forma de convencionalismo. Este último se caracteriza por tener lugar cuando no enfrentamos a diversos esquemas de referencia todos igualmente adecuados. Por otro lado, la IR significa la imposibilidad de siquiera un solo esquema de referencia adecuado: “I take Quine's inscrutability thesis to be the thesis that no theory of reference is posible." (Field, 1975, p. 398) Así (si hacemos caso a Field), llegamos a la conclusión de que la IR no sólo no da pie a la formulación de la OR sino que socava la idea o noción misma de referencia. ${ }^{71}$ En este sentido toda la discusión sobre el carácter instrumentalista de la OR, su diferencia respecto del convencionlismo ha sido en vano, pues la IR impide el primer paso, a saber: IR $\rightarrow$ OR.

Toda esta digresión no ha sido del todo inútil, pues nos ayuda a entender la concepción de Field sobre la referencia y su descontento con el tratamiento que Quine da a ella. Field hace una buena aportación en la clarificación de la tesis indeterminista. Pero más importante es que el problema planteado

\footnotetext{
${ }^{69}$ La motivación detrás de este requisito radica en el rechazo de cualquier clase de hechos semánticos (tanto Quine como Field comparten esta actitud).

${ }^{70}$ En base a estos dos requisitos, Field (1975 pp. 400-1) interpreta la diferencia entre el convencionalismo y la IR de la siguiente manera: "Notice how different this thesis is from the conventionalist thesis discussed earlier: the conventionalist thesis seemed to suggest that many reference schemes satisfied Requirements A and B; the inscrutability thesis (as I am interpreting it) says that no schemes satisfy both these Requirements."

${ }^{71}$ En primer lugar, a Field le parece inaceptable que Quine piense que "the existence of indeterminacy shows that scientific terms are "meaningless" [and denotationless] except relative to [their] own theory; meaningless [and denotationless] intertheoretically." (Field, 1973, p. 480) Si esta propuesta relativizadora está equivocada (y la IR, por tanto, es verdadera), entonces Field cree que la noción de referencia no tiene sentido.
} 
por la IR estímulo a Field a introducir como soluciones sus tesis de la referencia parcial y la teoría causal de la referencia ${ }^{72}$ aunque éstas no resuelven (o eso defiendo) la dificultad originada por la IR.

\subsection{Field, la noción de referencia parcial y la teoría causal de la referencia.}

La teoría causal pretende resolver la inquietud de Quine sobre el sinsentido acarreado por la IR. También, fue pensada con el propósito de poner de manifiesto la conexión objetiva entre palabras y objetos (independientemente de la conexión oraciones-mundo, muy enfatizada por Quine y Davidson). Sin embargo, la teoría causal de la referencia y la IR no están disociadas. La IR, tal como Field la concibe, implica una relación causal determinada entre una palabra y por lo menos dos objetos. De entre los objetos a los que refieren los términos, éstos últimos refieren parcialmente (de forma determinada) a cada uno de los primeros, y una conexión causal les relaciona.

\subsubsection{La noción de referencia parcial explicada en el contexto de un cambio de teoría.}

Los pioneros de la teoría de la referencia o semántica referencial (como la llama Field) -Frege, Carnap y Tarski- empleaban los conceptos de denotación y extensión para dotar de sentido a las nociones más controversiales (en su tiempo al menos) de verdad y falsedad. Esta forma de abordar el asunto parece la más razonable siempre y cuando no nos veamos inmiscuidos en los problemas (para los conceptos de referencia, verdad, etc.) derivados de un cambio de teoría. Las revoluciones científicas (usando la terminología de Kuhn) acarrean serios problemas para la determinación de la referencia. En otras palabras, el cambio de paradigma científico crea IR. Nos hallamos entonces frente a un problema el cual admite diversas e incompatibles soluciones. Field propone la noción de referencia parcial como solución,

\footnotetext{
72 Aunque probablemente el punto de partida haya sido mal planteado (ya que Field parte del presupuesto de que la IR imposibilita la existencia de una noción de referencia), las nociones subsecuentes resultan bastante interesantes.
} 
la cual, es, presuntamente, capaz de lidiar con el problema de la IR y, por consiguiente, esclarecer el fenómeno del cambio de teoría.

El cambio teórico elegido (por Field) para ejemplificar el fenómeno comprende la mecánica newtoniana (o mecánica clásica), la teoría de la relatividad y la mecánica cuántica. La indeterminación a examinar se encuentra en el término "masa" tal y como lo usaba Newton. El mismo Newton y sus sucesores no contaban con los recursos para decidir entre cuál de las siguientes "extensiones" denotaba aquel término: masa relativista o masa en reposo (nosotros tampoco). Para entender el origen y la trascendencia de la indeterminación de la referencia necesitamos antes comprender los términos involucrados. Sin embargo, el objetivo principal aquí se restringirá a exponer las fórmulas y nociones esenciales para entender la diferencia entre el término newtoniano y sus contrapartes contemporáneas.

Newton aceptaba las siguientes afirmaciones:

(A) La masa de un cuerpo es igual a dos veces su energía cinética entre el cuadrado de su velocidad $\left(\mathrm{m}=2 \mathrm{E}_{\mathrm{c}} / \mathrm{v}^{2}\right) ;^{73}$

(B) La masa se conserva en todas las interacciones;

(C) El momento es igual a masa por velocidad $(\mathrm{p}=\mathrm{mv})$; despejando la fórmula tenemos masa es igual a momento entre velocidad $(\mathrm{m}=\mathrm{p} / \mathrm{v})$;

(D) Para cualesquiera dos marcos de referencia, la masa respecto de un marco es igual a la masa respecto del otro marco. ${ }^{74}$

\footnotetext{
${ }^{73}$ La fórmula de la energía cinética se consigue si despejamos la fórmula de la masa. Así, la energía cinética es igual a un medio por masa y velocidad al cuadrado entre dos $\left(E_{c}=1 / 2 m^{2}\right)$.

${ }^{74}$ Field admite que este principio no aparece formulado explícitamente por Newton, pero se hacía uso de él de forma implícita tanto por Newton como sus sucesores.
} 
Estas afirmaciones resultan inadecuadas desde la perspectiva de la física contemporánea. En la actualidad, la definición de masa depende de si ésta se encuentra en reposo o movimiento. Así:

Masa relativista $(\mathrm{R})^{75}$ : energía total dividida por la velocidad de la luz al cuadrado $\left(\mathrm{m}=\mathrm{E} / \mathrm{c}^{2}\right) .{ }^{76} \mathrm{La}$ masa varía dependiendo del marco de referencia, pues, aunque la velocidad de la luz permanece constante en cualquier marco, la energía del cuerpo varía de marco a marco en función de su velocidad (y a una variación en la energía del cuerpo corresponde una variación en su masa).

Masa en reposo $(\mathrm{P})^{77}$ : la masa del cuerpo es igual a su energía-no-cinética dividida por el cuadrado de la velocidad de la luz. La velocidad de la luz permanece constante, y la energía cinética permanece constante (pues el cuerpo no se mueve); por lo tanto la masa en cuerpo se conserva en todos los marcos de referencia.

Las cuatro oraciones precedentes ((A), (B), (C) y (D)) sirven para ilustrar la indeterminación de la referencia al pasar de la mecánica newtoniana a las nuevas teorías físicas. Según la teoría de la relatividad de Einstein, la conjunción de las afirmaciones (C) y (D) resulta falsa en tanto implica inmutabilidad de la masa sin importar el marco de referencia ((D) es falso), pero, como sabemos, la masa relativista depende del marco. Por otro lado, incluso si el término "masa" se refiere a masa en reposo la conjunción seguiría siendo falsa ya que la fórmula $\mathrm{p}=\mathrm{mv}($ despejada queda como: $\mathrm{m}=\mathrm{p} / \mathrm{v})$ implica que el cuerpo se mueve (en este caso (C) es falso). La conjunción de (C) y (D) es incompatible y no hay forma de determinar cuál de los dos coyuntos es verdadero y cual falso, simplemente no hay un fact of the matter para la referencia.

\footnotetext{
75 “(R)" se introduce a modo de abreviación para "masa relativista", lo mismo que "(P)" para "masa en reposo"

${ }^{76}$ Obsérvese que $\mathrm{m}=\mathrm{E} / \mathrm{c}^{2}$ es la transformación de la famosa ecuación de Einstein, la cual postula la equivalencia entre masa y energía: E= $\mathrm{mc}^{2}$.

77 También se le denomina masa invariante, pues no varía con el cambio de marco de referencia.
} 
En vista de estos dos nuevos conceptos de masa ¿a cuál se refería el término "masa” empleado por Newton? Al parecer ningún hecho relevante existe que determine la elección, por tanto nos hallamos frente a un caso real de indeterminación de la referencia. Pero antes de admitir esta consecuencia, examinemos algunas posibles alternativas. Algunos querrían defender la idea según la cual Newton sí se refería a algo, a un $x$; a esta posición, siguiendo a Field, la llamaremos "tesis positiva". Otros por el contrario otros dirían que el término newtoniano no se refería a nada en absoluto; esta es la "tesis negativa". Field mantiene que ninguna de estas alternativas resulta correcta. La única y mejor forma de hacer justicia a las palabras de Newton está en asignarles ambos referentes (R) y (P), es decir: "masa" denota $(\mathrm{R})$ y $(\mathrm{P})$, aunque parcialmente.

Del lado de la tesis positiva nos encontramos con la propuesta de Kuhn (1970). Según él, Newton se refería a una entidad distinta de la postulada por las nuevas teorías físicas. Newton hablaba de una entidad llamada por Kuhn "masa newtoniana”. Si aceptamos la explicación kuhniana, concedemos la existencia de un cambio de ontología simplemente como consecuencia del cambio de teorías. Esta consecuencia del análisis kuhniano no parece muy atractiva, pues nos conduce a una especie de relativismo incómodo para muchos filósofos. Bajo esta perspectiva, la entidad referida por Newton comparte, no obstante, algunas propiedades con la $(\mathrm{R})$ y la $(\mathrm{P})$. Al igual que $(\mathrm{P})$ la masa newtoniana no depende de los marcos de referencia y de forma similar a (R), el cuerpo lleva cierta velocidad. Asimismo, la masa newtoniana se distingue de $(\mathrm{R})$ y de $(\mathrm{P})$ en que no se conserva en todas las interacciones y se puede expresar con la fórmula $\mathrm{m}=2 \mathrm{E}_{\mathrm{c}} / \mathrm{v}^{2}$. Según Field, quizás haya alguna manera de hablar de la existencia de la masa newtoniana como significado, pero no de su existencia como referente de alguna expresión lingüística, pues la teoría de la relatividad y la física cuántica implican su no-existencia en la forma de una entidad en el mundo. Así, Field (1973, p. 470) llega a la polémica conclusión de que Newton 
se refería parcialmente a los conceptos contemporáneos $(\mathrm{R})$ y $(\mathrm{P})$, mas no a la presunta masa newtoniana. ${ }^{78}$

Aún queda una segunda solución. Parece que Newton no se refería a nada después de todo, y es que no existe en el mundo entidad tal en el mundo como la masa newtoniana. El problema con esta alternativa es que nos obliga a asignar valores de verdad inadecuados a multitud de afirmaciones hechas por Newton. Field (1973) considera la siguiente afirmación teórica newtoniana: ${ }^{79}$

(N) Para acelerar un cuerpo uniformemente de forma que cambie de la velocidad $v_{l}$ a la velocidad $v_{2}$ entre más grande el cuerpo más fuerza se requiere.

Ciertamente $(\mathrm{N})$ es verdadera tanto en la física clásica como en la física contemporánea, pero ¿seguiría siendo verdadera si el término "masa” no tuviera referencia? Presumiblemente, la respuesta es no. La mayoría de los filósofos del lenguaje (Frege, Russell y Quine) han mantenido una de dos posiciones respecto a la ocurrencia de términos carentes de referencia dentro de oraciones: 1) las oraciones carecen de valor de verdad; 2) las oraciones son falsas. Ahora bien, (N) no carece de valor de verdad ni es falso. Por tanto, el término "masa" refiere a algo. ${ }^{80}$

Field cree encontrar ya en la filosofía de Quine los primeros pasos hacia la idea de la IR en el contexto del cambio de una teoría científica, así como la importancia de relativizar la verdad y la referencia a una teoría. En Word and Object (pp. 23-4) Quine afirma lo siguiente:

\footnotetext{
${ }^{78}$ En palabras de Field: "I'm denying that there is or ever was such a quantity as "Newtonian mass," and hence I'm denying that Newton could have ever referred to "Newtonian mass" when he used the word 'mass'." (1973, p. 470)

${ }^{79}$ Otras afirmaciones-newtonianas (no porque Newton las haya proferido de hecho, sino porque se encuentran implícitas en la teoría y práctica del mismo Newton y sus sucesores) empleadas por Field (1973) son las siguientes: "La masa del objeto A está entre 1.21 y 1.22 kilogramos y "para acelerar uniformemente un cuerpo de la velocidad $v_{l}$ a la velocidad $v_{2}$, entre más masa este contenida en el cuerpo, mayor fuerza se requiere.

${ }^{80}$ Así, la concepción negativa sobre la referencia de "masa" resulta incompatible con una adecuada asignación de valores de verdad (incluso si consideramos $(\mathrm{N})$ como una afirmación aproximadamente verdadera).
} 
If there were $[. .$.$] an unknown "ideal theory" \theta$ (say a limit that would be attained by applying scientific method forever) which we could regard as completely true, still this would not settle the truth [...] that any single sentence $S$ is true if it or a translation belongs to $\theta$, for there is in general no sense in equating a sentence of a theory $\theta$ with a sentence $S$ given apart from $\theta$. Unless pretty firmly and directly conditioned to sensory stimulation, a sentence $S$ is meaningless except relative to its own theory; meaningless intertheoretically.

Quine se adelanta a Field en advertir la IR de los términos newtonianos en relación a nuestra teoría física actual $^{81}$ (de igual modo, Quine ya reconocía la indeterminación de la referencia de nuestros términos en relación a la mecánica newtoniana). De hecho, esta cita sugiere la indeterminación de nuestros propios términos en relación a una teoría posterior. Nuestros términos estarían determinados sólo dentro de la teoría, pero en relación a una teoría futura únicamente podemos esperar indeterminación (de forma análoga a la indeterminación del término "masa" en relación a nuestra teoría física contemporánea). Si tomamos en cuenta todos los aspectos anticipados por Quine, podemos considerar la(s) teoría(s) de Field un refinamiento de la filosofía quineana: se aceptan diversas tesis, y se trata de evitar incoherencias entre las mismas. Aunque, lo realmente original en la propuesta de Field corresponde a la noción de referencia parcial. Sin embargo, Field llega a esta tesis partiendo de la teoría de la referencia quineana.

Tal teoría implica (según Field) lo siguiente:

a) No podemos traducir una oración de la teoría física newtoniana a una oración de nuestra teoría sin indeterminación.

b) No existe un fact of the matter para decir si la oraciones newtonianas son verdaderas o falsas. ${ }^{82}$

\footnotetext{
${ }^{81}$ Respecto a nuestra teoría física, no existe un fact of the matter para decidir la verdad of falsedad de las oraciones (C) y (D), o a qué refiere el término "masa" en ellas contenido.

${ }^{82}$ Según Field: "Newtonian physics as a whole is objectively false, but there is no fact of the matter as to how the falsity of the theory as a whole is to be distributed among the individual sentences of the theory." (1973, p. 474)
} 
a) y b) implican el fracaso del concepto de referencia para explicar la noción de verdad; la imposibilidad de una teoría de la referencia (como vimos arriba), por lo tanto necesitamos de una solución. Field propone, entonces, la noción de referencia parcial: "I want to say that Newton's word 'mass' partially denoted proper mass and partially denoted relativistic mass; since it partially denoted each of them, it didn't fully (or determinately) denote either.” (Field, 1973, p. 474) La OR también parece resolver el problema, pero como ya hemos visto, esta tesis entraña una incoherencia prima facie insuperable. Así:

(HI) Newton's word 'mass' partially denoted proper mass and partially denoted relativistic mass and didn't partially denote anything else. (Field, 1973, p. 476)

Ahora bien, la indeterminación de la referencia de los términos newtonianos afecta el valor de verdad de las oraciones donde aparecen esos términos. Por ejemplo, dada la afirmación:

(O) La masa es independiente del marco de referencia.

La oración es parcialmente verdadera y parcialmente falsa: "when Newton uttered this sentence what he said was sort of true and sort of false." (Field, 1973, p. 476) Puesto que el término "masa" se refiere parcialmente a masa en reposo, $(\mathrm{O})$ es verdadera. Pero falsa en tanto $(\mathrm{O})$ se refiere parcialmente, también, a masa relativista, pues en este caso la masa depende del marco. Así, la IR tal como Field la entiende nos lleva a la indeterminación de la verdad. ${ }^{83}$

La revolución científica produce un refinamiento de los términos de la teoría: "the set of things that it partially denoted after $r$ is a proper subset of the set of things it partially denoted before." (Field, 1973, p. 479) ${ }^{84}$ Las revoluciones científicas no implican necesariamente el refinamiento de los términos, pero el acaecimiento de la refinación revela una característica importante no sólo de las teorías científicas

\footnotetext{
${ }^{83}$ La oración (C), por ejemplo, no tiene un valor de verdad determinado, debido a la IR.

${ }^{84}$ Donde $r$ corresponde a la revolución científica.
} 
pasadas, sino también de nuestras teorías actuales (y si generalizamos un poco podemos incluir a todo nuestro lenguaje), a saber: los términos están referencialmente indeterminados. ${ }^{85}$ En un primer momento, Field, descarta la solución ofrecida por la OR, luego ofrece una salida vía la introducción del nuevo concepto semántico: referencia parcial. Pero no se detiene ahí. Inmediatamente trata de ligar este concepto a una teoría causal de la referencia, a fin de dar sentido fisicalista a la noción de referencia, a la relación entre palabras y objetos, a las relaciones de denotación y significación:

On my view they are perfectly objective relations which hold between terms in the one hand and extralinguistic objects or sets of objects on the other. The existence of referential indeterminacy shows only that the relations of denotation and signification are not well-defined in certain situations and that if we want to apply semantics to those situations we have to invoke the more general relations of partial denotation and partial signification. But these more general relations (like the less general ones; in the situations in which those less general relations are well defined) are perfectly objective relations between words and extralinguistic objects (or sets of objects), and are not in any interesting sense "relative to the conceptual scheme." (Field, 1973, p. 480)

Aún falta verificar si la teoría causal de la referencia más el concepto de determinación parcial de la referencia logran resolver el problema de la IR quineana. Asimismo analizaremos las razones presentadas por Davidson para rechazar la solución fundada en una teoría causal. También discutiremos como una reformulación de la OR podría proporcionar una caracterización adecuada de lo que está en juego.

\footnotetext{
${ }^{85}$ Así, según Field: "If I am right in thinking that denotational refinement is a fairly common feature of scientific revolutions, that suggests that future scientists may very well refine many of our current scientific terms, and hence that many of our scientific terms are referentially indeterminate. (In fact induction from the indeterminacy of terms in earlier theories may suggest that science will never reach the stage all of its terms are perfectly determinate).” (1973, p. 479) Véase también: Field; 2001, p. 236, y 2000, pp. 2-3.
} 


\subsubsection{Referencia parcial y la teoría causal de la referencia.}

Field, como buen fisicalista, concuerda con Quine en su rechazo al mito del museo, pero difiere en su posición respecto a la IR. Contra Quine, Field (1972 p. 373) no cree en la primacía de las oraciones sobre las palabras en lo que respecta a la relación lenguaje-mundo respecta. Consecuentemente, propone un nuevo enfoque capaz (según él) de evitar la IR en su forma quineana y al mismo tiempo de evitar la hipostatización de entidades semánticas. Así, su solución se halla en una teoría causal de la referencia y la introducción de la noción de determinación parcial de la referencia. Ambos conceptos en conjunto deberían proveernos de los medios necesarios y suficientes para dar sentido a la noción de referencia y,

en particular, a la idea de referencia parcial. Éstas a su vez dan sentido, de manera indirecta, a la IR, aunque no en la forma que Quine hubiera esperado. Asimismo, Field parece evitar la incoherencia entre IR y OR, y una inconsistencia, menos obvia, entre la OR, por un lado, y la teoría de verdad de Tarski por el otro.

Field cree en la posibilidad de una teoría correspondentista de la verdad aun frente a los problemas planteados por la indeterminación. Su creencia toma fuerza de la convicción fisicalista de que existen relaciones causales, las cuales ligan hechos del mundo (específicamente objetos) con expresiones lingüísticas. La teoría causal de la referencia le permite dar plausibilidad fisicalista a la nueva relación de referencia parcial. La idea general es que el término "gavagai" denota parcialmente dos objetos: conejo y parte no separada de conejo. Los referentes se conectan con el término vía una relación causal. Así se preservaría la fuerza explicativa del esquema desentrecomillador de Tarski, aunque en lugar de tener la forma “" $F x$ ” es verdadero sii $F x$ " tendría la siguiente: ““ $F x$ ” es verdadero sii $F x$ y $F \varphi x$ " (donde $\varphi x$ es una permutación de $x$ ). En general, podemos hablar de referencia parcial para diversos tipos de términos lingüísticos: de los términos singulares decimos que denotan parcialmente objetos, y de los predicados que significan parcialmente sus extensiones. 
Si creemos a Field, la tarea de traducir teorías científicas del pasado a sus contrapartes contemporáneas, como vimos en la sesión anterior, exige la aplicación de las nociones de denotación parcial, significación parcial y extensión parcial. Por otro lado, la labor de traducción nos ayuda a pensar cómo podríamos (según Field) insertar estas nociones en una teoría de la verdad. Más arriba advertíamos la posible traducción del término newtoniano "masa" como "masa relativista" o "masa en reposo", ahora ¿Cómo luciría la traducción del término newtoniano "masa" dentro de una oración? Todo apunta a que los valores de verdad no permanecerían intactos. Considérense las siguientes oraciones (imagínese que Newton o algún newtoniano las pronuncio o pensó):

(H) Momento es igual a masa por velocidad.

(I) Masa es invariante, independiente del marco de referencia.

Si traducimos "masa" como denotando masa relativista, entonces (H) es verdadera y (I) es falsa. Por otro lado, si nuestra traducción asigna el referente masa en reposo al término newtoniano "masa", entonces $(\mathrm{H})$ es falsa y (I) es verdadera. Los valores de verdad en cada interpretación del término "masa" resultan opuestos. Ahora bien, si creemos a Quine y a Field, no existe un hecho que decida cuál de las traducciones es la correcta, y por tanto: “no fact of the matter as to which of Newton's sentences [...] was strictly true.” (Field, 1974 pp. 209-10) Así, el término newtoniano "masa" denota parcialmente tanto a la masa relativista como a la masa en reposo (aunque no las denota de forma completa o determinada a cada una por separado). ${ }^{86}$

Dada una estructura $m$ (o esquema de referencia) para un lenguaje $L$, la IR reconsiderada implica la existencia de varias estructuras cada una de las cuales concuerda parcialmente con la semántica de $L$. Así, cada término de $L$ denota parcialmente las entidades que por lo menos dos estructuras, a saber $m$, o

\footnotetext{
${ }^{86}$ La noción de denotación parcial se aplica a términos que tengan una aplicación indeterminada, así como a los que tienen una determinada, es decir, la expresión “denotación parcial” denota parcialmente a i) denotación normal, y ii) denotación parcial. De hecho, para Field, la noción de denotación constituye una generalización de la noción de denotación parcial.
} 
$m^{*}$ o $m^{* *} \ldots$ le asigna. ${ }^{87}$ Así, $m$ funge como una función que asigna objetos o entidades extralingüísticas a términos lingüísticos. De esta manera, la noción de correspondencia entre los objetos asignados por la estructura $m$ y la semántica del lenguaje $L$ no pierde sentido dada la IR.

¿Cómo enlazar lo anterior con el concepto de verdad? Bueno, Field introduce la noción de verdad de una oración en una estructura, según la cual, una oración sería verdadera en una estructura $m$ si todos los términos en cierta oración denotaran o significaran sólo las entidades asignadas por $m$. Veamos un ejemplo donde $m$ no concuerda con la semántica de $L$ y por tanto la oración no es verdadera. Dado el término "masa" del leguaje $L$, nuestra estructura $m$ le asigna el referente rinoceronte, y al predicado "es invariable" le asigna el conjunto de los artrópodos; entonces la oración "la masa es invariable" es verdadera si y sólo si un rinoceronte es un artrópodo. Todo esto nos lleva a desechar $m$ como errónea, pues de hecho, siguiendo a Field: la oración mencionada dada la estructura $m$ es falsa. Pero este resultado es inapropiado. De ahí que Field sugiera restringir nuestra atención únicamente a estructuras concordantes con la semántica de nuestro lenguaje. ${ }^{8}$ En el caso de los términos referencialmente indeterminados debemos concentrarnos en estructuras que por lo menos concuerden parcialmente con la semántica de nuestro lenguaje. Field lo plantea de la siguiente manera:

(8) A sentence of $L$ is true if and only if it is true-relative-to- $m$ for every structure $m$ that partially accords with the semantics of $L .(1974$, p. 212)

Veamos algunos ejemplos proporcionados por el mismo Field, donde se echa mano de las oraciones $(\mathrm{H})$ e $(\mathrm{I})$ arriba mencionadas, y téngase en cuenta la doble referencia (parcial) del término "masa" tal como lo usaba Newton.

\footnotetext{
${ }^{87} \mathrm{Si}$ los términos del lenguaje están completamente determinados, entonces sólo una estructura concuerda con la semántica del lenguaje.

${ }^{88} \mathrm{El}$ hecho de que la referencia esté indeterminada no significa que uno deba aceptar estructuras tan ajenas al uso común como el caso expuesto, o al menos eso cree Field.
} 
Cuando Newton profirió: “(H) o (I)” afirmaba algo verdadero.

“(H) y (I)” afirmaba algo falso.

“(H)” afirmaba algo ni verdadero ni falso.

“(I)” afirmaba algo ni verdadero ni falso.

De esta manera, Field consigue insertar términos indeterminados en una teoría de la verdad vía la noción de referencia parcial. La vieja definición de verdad la caracteriza mediante los conceptos de denotación y satisfacción o significación (para utilizar la terminología de Field) determinados, es decir: no está capacitada para lidiar con términos referencialmente indeterminados. En cambio, la definición de verdad propuesta por Field da cuenta de esos términos. Así, una oración en $L$ es verdadera: “if and only if it is true-relative-to- $m$ for every structure $m$ that partially accords with the semantics of $L$." (Field, 1974, p. 212) La oración "la masa es independiente del marco de referencia” o la oración (O) (en la sección precedente) es verdadera o falsa dependiendo de la estructura, es decir, de la referencia asignada al término "masa". Si refiere a masa en reposo la oración es verdadera, si refiere a masa relativista la oración es falsa. Así, "since these truth values differ, the sentence is not determinately true or false." (Field, 1973, pp. 477-8)

Aparentemente, Field adelanta una tesis relativista similar a aquella de Quine. Sin embargo, esta apariencia se disipa cuando nos percatamos de ciertas diferencias fundamentales entre ellas. Para Quine, el término "masa" en la oración $(\mathrm{O})$ refiere determinadamente a masa relativista o masa en reposo una vez la relativizamos a una teoría dada, pero no refiere a una y a otra a la vez. En cambio, para Field la referencia del término en cuestión sigue indeterminada aun cuando cambiemos nuestra semántica tradicional por aquella donde ocurre la noción de referencia parcial. Field conserva una noción de IR. Sin embargo, ésta difiere de la quineana al presuponer un especie peculiar de determinación de la 
referencia: precisamente aquella que denominamos referencia parcial. ${ }^{89}$ Aunque Quine (1969) parece percatarse de la persistencia de la IR aun relativizándola a una teoría, IR y OR conviven en su filosofía, y aunque se muestra en ocasiones insatisfecho con el resultado, no intenta remediar el problema, aún más, él mismo parece no considerarlo un problema. Para Field, en cambio, la IR y la OR (tal como las concibe Quine) se excluyen mutuamente. La relativización sucede sólo cuando introducimos la noción de referencia parcial; de esta manera los términos refieren determinadamente ${ }^{90}$ a por lo menos dos entidades asignadas por las estructuras correspondientes. Así, la relativización de Field preserva un tipo de IR: los términos referencialmente indeterminados refieren determinadamente a por lo menos dos objetos. Resumiendo: la relativización quineana pretende que los términos newtonianos refieran determinadamente sólo a un objeto; Field conserva la indeterminación de los mismos pero admite un tipo de determinación cuando se introduce la noción de referencia parcial. ${ }^{91}$

Ahora bien, el fenómeno de la indeterminación también afecta a los términos ligados con el término indeterminado. Para ellos, hablamos de indeterminación correlativa (o indeterminación holista; Field, 2000), para la cual cambia un poco nuestra definición de verdad. La idea central detrás de esta nueva noción consiste en una especie de dependencia entre términos singulares y predicados: la extensión de uno depende de la extensión del otro, este último siendo el más básico. Si el término más básico (o

\footnotetext{
${ }^{89}$ El término "masa" está indeterminado, pero refiere de forma parcial y determinada a masa relativista y masa en reposo.

${ }^{90}$ A manera de ejemplo, Field hace notar que: “In this way we can get the result that even if 'entropy' partially refers to many things (and hence doesn't determinately refer to anything), still the sentence “"entropy' refer to entropy and nothing else” comes out true. (Indeed, determinately true: true on every acceptable combination of the partial referents of 'entropy' and 'refers'). (1998, p. 254)

${ }^{91}$ Field cree, así, habernos proveído de una teoría de la verdad capaz de lidiar con expresiones referencialmente indeterminadas y al mismo tiempo dar cuenta de lo que ocurre en los cambios de teoría: "I have established the utility of the concept of partial denotation in dealing with theory change, and shown that scientific revolution can affect the semantic features of scientific terms in more complicated ways than many philosophers have allowed [...] $t$ has undergone a denotational refinement during $r$; i.e., the set of things that it partially denoted after $r$ is a proper subset of the set of things it partially denoted before. This added possibility is of considerable importance for debates about "incommensurability" in science: it shows that we can accept the claim that we can't always equate a term from one theory with a term from a later theory, and still deny the incommensurability thesis, i.e., the thesis that the earlier and later terms cannot objectively be compared with respect to referential properties." (Field, 1973, p. 479)
} 
término base) está indeterminado, entonces los términos dependientes o correlativos también lo estarán. En la oración “el conejo $x$ y el conejo y son idénticos", "son idénticos" constituye el término (predicado en este caso) base y “conejo $x$ ” y “conejo y” los términos correlativos. La indeterminación de los términos independientes es una función de la indeterminación del termino base. Éste denota parcialmente la relación de identidad y la relación de paridentidad o identidad de partes. Si el término base está indeterminado, también lo estarán los términos correlativos. Si en la oración anterior asignamos a “conejo" su denotación parcial parte-no-separada-de-conejo y a "son idénticos" su significación parcial: paridentidad, obtendríamos algo parecido al siguiente enunciado: "las partes-no-separadas-de-conejo $x$ y las partes-no-separadas-de-conejo y son idénticas”.

La dependencia funcional entre los términos nos permite correlacionar las extensiones parciales del término base con el término correlativo. Es decir, si el término base denota o significa paridentidad entonces la denotación de los términos correlativos son partes; si el término base denota identidad, entonces la denotación de los términos correlativos no puede estar dada por partes sino por unidades, etc. De esta forma, Field refina el concepto de referencia parcial, y parece proveernos de una definición de verdad más adecuada. Sin embargo, la propuesta presupone un requisito fundacional, a saber: siempre debemos contar con algún término base. Tal base podría sustentarse en otra base y así sucesivamente, pero resulta necesario llegar a un punto fijo independiente. ${ }^{92}$ Para lidiar con la indeterminación correlativa de la referencia, la definición de verdad consiste básicamente en lo siguiente:

a) Una oración $L$ es verdadera si y sólo si es verdadera en relación a una estructura $m$ que parcialmente concuerda con la semántica del lenguaje $L$.

\footnotetext{
${ }^{92}$ Una crítica obvia seria cuestionar la determinación del término base sin reparo, pues la identidad "[...] is of a piece with ontology. Accordingly it is invoved in the same relativity." (Quine, 1969, p. 55), es decir, si tomamos a "la identidad" como un término general concreto, la IR afecta la determinación referencial del término base. En el tercer capítulo abordaremos este problema con la propuesta de Field.
} 
b) Para que la estructura $m$ concuerde con la semántica de $L$ se requiere que:

b1) todo término base $c$ de $L$ denote o parcialmente denote (o signifique) la entidad que la estructura $m$ le asigna.

b2) todo término correlativo $d$ de $L$ denote (o signifique) la entidad que la estructura $m$ le asigna a $d$ en relación a la correlación de $\mathrm{m}(\mathrm{b}(\mathrm{d}))$; donde $\mathrm{c}=\mathrm{b}(\mathrm{d})$, es decir, el término $c$ es la base del término $d$ ".

c) El requisito fundacional.

Field cree en la existencia de dos referentes del término "denotar": denotar y denotar parcialmente. Así el término “denotar” está indeterminado entre i) denotar y ii) denotar parcialmente. ${ }^{93}$ No todo nuestro lenguaje (o teoría) sufre de indeterminación, existen casos donde la aplicación del término "denotar" no conlleva indeterminación alguna, sino que se refiere determinadamente a (i). Lo anterior constituye una nueva forma de definir o entender la expresión “denotar". En el lenguaje diario, esta expresión refiere determinadamente a (i), y no hay mayor problema. Pero si la teoría de Field sobre la indeterminación de ciertas expresiones es verdadera, entonces en el caso en que nuestros términos estén indeterminados, el término “denotar” está indeterminado entre (i) y (ii). Al emplear la expresión “denotación parcial” nos referimos a la denotación parcial (a: ii); el término indeterminado es “denotar"94 no "denotar parcialmente", este último si está determinado. El requisito fundacional implica que la IR termina cuando encontramos algún término base. Sin embargo, este requisito parece vulnerable a la IR ¿Cómo determinamos la existencia de un término base genuino?

Ahora tratemos de ver la relación entre la noción de referencia parcial y la teoría causal de la referencia ¿Cómo dar un sentido fisicalista-causal a estos nuevos conceptos introducidos por Field? Bueno, Field nos ha brindado argumentos persuasivos sobre porque la teoría de la verdad tradicional no

\footnotetext{
${ }^{93} \mathrm{O}$, lo que es lo mismo: determinación de dos o más referentes.

${ }^{94} \mathrm{El}$ término "denotar" no siempre está indeterminado, a veces refiere a la denotación determinada. Este es el caso cuando los términos de $L$ no están referencialmente indeterminados. El problema es que si Quine tiene razón siempre están.
} 
sirve para dar cuenta de la semántica de las teorías científicas y del lenguaje en general, y ha puesto en la mesa una alternativa bastante atractiva: si las expresiones de nuestro lenguaje están ligadas parcialmente (refieren parcialmente) causalmente a objetos entonces tendríamos una poderosa forma de dar cuenta de aparentes e incómodas dificultades en la traducción de teorías y lenguajes.

Field confía en la capacidad de sus nuevas nociones para proveernos de una teoría adecuada de la verdad, y dotar de sentido fisicalista a las nociones referenciales. De hecho, él cree en la existencia de una relación causal entre palabras y objetos que yace a la base de la idea de determinación parcial de la referencia. La línea causal que liga expresiones del lenguaje con objetos determina parcialmente la referencia de dichas expresiones:

Even if there are no naturalistic facts that fully determine the referents of these words or concepts, surely there are naturalistic facts that partially determine the referents. (Surely facts about our use of 'insanity' determine that the word doesn't stand for lubricating jelly). [...] empirical notions like 'red' and 'cat' and 'longer than' are far from being wholly indeterminate: 'red' definitely fails to be true of green things, and 'cat' definitely fails to be true of cherries [...] our practice with words like 'red' includes not only theoretical principles, but includes also an observational practice which causally ties the extension down. Other physical predicates, say 'neutrino', are less tied to observational practice, but the theoretical principles governing them include words that are more tied to observational practice, and this does a lot to fix their extension. (Field, 1998, p. 269)

Field cree, entonces, que los términos físicos están ligados directa o indirectamente al mundo. Sin embargo, cabe mencionar que a veces se muestra escéptico sobre sus propias teorías. En ocasiones, parece como si aceptara la imposibilidad de superar el problema de la indeterminación:

[...] any causal links between rabbits and uses of 'rabbit' are also causal links between rabbit stages and uses of 'rabbit', between undetached rabbit parts and uses of 'rabbit'. (Field, 1975, p. 399-; véase también p. 400) 
Aparentemente, Field vacila sobre la capacidad de la teoría causal de la referencia para evitar la IR quinena. El que este filósofo haya llegado a tal conclusión después de tanto esfuerzo por demostrar la falsedad de la tesis de la IR muestra que no es fácil refutarla. ${ }^{95}$ El capítulo que sigue no intenta, pues, mostrar una nueva forma de evitar la IR, sino más bien una manera de hacerla compatible con la OR, aunque, para este propósito debemos modificar un poco las tesis (y nuestra concepción de la relación existente entre ellas) o por lo menos una de ellas (OR).

95 De hecho, si creemos a Field, la IR estaría íntimamente emparentada con la vaguedad y, entonces, sería aun más difícil librarse de las dificultades que acarrea: “for surely ordinary vagueness is a kind of indeterminacy, and surely vagueness is abiquitous.” (2000, p. 5) 


\section{CAPÍTULO III}

\section{LA CRÍTICA DE DAVIDSON: LA RELATIVIDAD QUINEANA VS LA RELATIVIDAD DAVIDSONIANA}

En este capítulo se vuelven a enumerar brevemente las razones por las que la IR y la OR resultan incompatibles. Apoyándose en las críticas de Field, Davidson llega a la misma conclusión sobre la imposibilidad de derivar la OR de la IR. Ambos concuerdan sobre la existencia de una inconsistencia en el pensamiento de Quine. Sin embargo, también favorecen una interpretación naturalista de la referencia (y de la semántica en general), y creen en la existencia de la IR (aunque por razones distintas), por lo cual, intentan evitar la inconsistencia quineana.

A pesar de las ventajas teóricas que la propuesta de Field pueda tener, la teoría causal se muestra vulnerable a los argumentos quineanos a favor de la IR. Aun cuando el objeto esté ligado a la palabra o término a través de una conexión causal, podemos reinterpretar la ontología de distintas formas. En otras palabras, la teoría causal de la referencia no garantiza en modo alguno que el término conejo (lo mismo vale para otros términos cualquiera) refiera únicamente a i) conejos, o, únicamente, a ii) partes-noseparadas-de-conejo, etc. Evidentemente, la teoría de la referencia parcial nos lleva a esta conclusión ¿entonces cuál es el problema? La dificultad principal radica en la posibilidad de reinterpretar nuevamente la ontología de i) y ii). 
Ahora bien, Davidson ofrece una solución al absurdo que preocupaba a Quine sin ninguna necesidad de recurrir a alguna teoría causal o noción parcial de referencia. La solución consiste en modificar la OR quineana de forma que no implique la determinación de la referencia. A esta nueva forma de relatividad la llamo "relatividad davidsoniana". La introducción de la nueva noción de relatividad resuelve las dificultades inherentes en la filosofía quineana. Evita la inconsistencia sin desechar la IR.

La propuesta davidsoniana tiene la virtud no sólo de evitar la inconsistencia que nos ha ocupado en los capítulos precedentes, sino de solucionar esa incoherencia preservando las doctrinas quineanas fundamentales sobre la relación lenguaje-mundo. Es decir, Davidson reformula la idea de relativización quineana partiendo de compromisos ontológicos, metodológicos y, en general, filosóficos del tipo presupuestos en la filosofía quineana. Entre estos se encuentran: i) énfasis en la primacía de oraciones sobre palabras en cuanto respecta a la conexión lenguaje-mundo; ii) aceptación de la traducción radical como un método científico-filosófico adecuado que nos permite caracterizar la génesis y naturaleza del significado y otras nociones semánticas de forma adecuada; iii) concepción holística sobre el lenguaje; iv) empatía, etc.

\subsection{La inconsistencia quineana y la teoría causal de Field.}

Como ya vimos, existe una incoherencia en la adopción simultánea de la IR y la OR. La contribución principal de Field reside en haberse percatado de este problema. Sin embargo, su solución no corre con la misma suerte, por el contrario enfrenta algunas dificultades planteadas por los argumentos aducidos a favor de la IR. Así, si bien Quine cometió un error al proponer la OR como solución a la IR, Field cometió un error al pensar que la teoría causal (aunada a la noción de referencia parcial) resolvería las dificultades. 


\subsubsection{Inconsistencia entre IR y OR.}

Como hemos visto en el primer capítulo, Quine sugiere la OR a modo de remedio para la IR, sin embargo Field nos ha ofrecido buenas razones para rechazar esta solución. Asimismo, la obra de Field ha influenciado a uno de los alumnos más cercanos a Quine: Donald Davidson. Éste ha retomado las tesis quineanas, las ha examinado a la luz de las críticas de Field, y ha intentado rehabilitarlas aunque con ciertas modificaciones. A pesar de su fuerte crítica, Field también rescata las tesis quineanas. Sin embargo, la caracterización davidsoniana rescata elementos esenciales del pensamiento filosófico de Quine: la primacía semántica de las oraciones sobre la referencia; la tesis holista sobre el significado (aunque un poco modificada), etc. Por esta razón, considero la propuesta davidsoniana más adecuada que la de Field. Asimismo, la teoría causal de la referencia, además de no solucionar el problema planteado por la IR, es vulnerable a la IR misma.

Para Davidson, la IR consiste en la imposibilidad de determinar a qué refieren los términos singulares, o de que son verdaderos los predicados de un lenguaje dado a partir de la evidencia conductual total. Es decir, diferentes esquemas de referencia se acoplan perfectamente con la evidencia disponible. ${ }^{96}$ Davidson no se muestra reacio a adoptar las tesis IR e IT; él mismo (1979, pp. 227-28) declara: "I think I accept both these mainly on the basis of argumets that I have learned from Quine”.

De acuerdo a Davidson, existen diferentes tipos de indeterminación, presentes todos en la obra de Quine, que nos llevan a la IR. Entre ellas se encuentran: 1) La indeterminación de la verdad y 2) La indeterminación de la forma lógica o aparato individuativo ${ }^{97}$ de nuestro lenguaje (términos singulares,

\footnotetext{
${ }^{96}$ Davidson emplea repetidamente el término "evidencia" como si la IR fuera una tesis epistémica, sin embargo, en el fondo, Davidson parece albergar una concepción no-epistémica. El problema, creo, resulta simplemente de un uso un tanto ambiguo de los términos.

${ }^{97}$ Davidson (1979, p.228) parece diferenciar la indeterminación del aparato individuativo de la IR (cf. Capítulo I).
} 
cuantificadores, predicados, etc.). ${ }^{98}$ Davidson también acepta la formulación de la IR vía funciones proxy. Recordemos brevemente en qué consisten. Dados dos manuales de traducción o esquemas de referencia (para usar el término de Davidson) para cada expresión donde ocurre un nombre que refiere a un objeto y un predicado que es verdadero de ese objeto, entonces mediante la aplicación de una función proxy, podemos reinterpretar el nombre de forma que refiere a un objeto distinto (se requiere simultáneamente el ajuste del predicado, para compensar la reinterpretación del nombre). Una vez realizada la reinterpretación, la expresión $x$ del esquema referencial 1 denota no al objeto $a$ sino a su proxy, o sea al objeto proxy-a. La reinterpretación o permutación (como la llama Davidson) conserva los valores de verdad intactos, más aún, las condiciones de verdad no sufren cambio. ${ }^{99}$

Las condiciones de verdad son las mismas para ambas interpretaciones. No obstante, existe un problema: no podemos tomarlas a ambas como verdaderas al mismo tiempo. ${ }^{100} \mathrm{~A}$ pesar de este predicamento, no contamos con razones para preferir una interpretación a otra, pues en la traducción lo

\footnotetext{
${ }^{98}$ Davidson ofrece medios para reducir el alcance de los diferentes tipos de indeterminación. Por ejemplo, para la indeterminación de la verdad Davidson apela a un principio de caridad de amplio alcance (más allá de la amplitud admitida por el principio de empatía quineano). El principio de caridad implica suponer no sólo coherencia lógica en las proferencias del hablante, sino, también, que las disposiciones verbales del nativo son semejantes a las nuestras dada cierta configuración de hechos en el mundo. El lingüista atribuye racionalidad al nativo o hablante: "Successful interpretation necessarily invests the person interpreted with basic rationality." (Davidson, 1991, p. 211) Ciertamente, este presupuesto metodológico (indispensable) ya existía en Quine: "Talk of projection (empathy, dramatic portrayal, Verstehen) has been a part of Quine's thinking about language learning and the propositional attitudes since the 1950s.” (Gibson, 1998b, pp. 673) Sin embargo su uso era un tanto restringido. En cambio, Davidson, lo emplea en toda la labor interpretativa y lo considera: "the foundation of intelligibility on which all interpretation rests." (Davidson, 1990c, p. 320) Esto no implica que no exista la irracionalidad; sí existe, pero en un segundo momento, como derivada. El segundo tipo de indeterminación se reduce si optamos por la aplicación de una teoría de verdad tarskiana como la base de una manual de traducción aceptable.

${ }^{99}$ Para ejemplificar el procedimiento, Davidson ofrece su propio ejemplo. Supónganse que cada objeto tiene una y sólo una sombra, ahora el término "Wilt" refiere a Wilt y el predicado "es alto" refiere a las cosas altas. Inmediatamente introduzcamos una función proxy $\theta$ tal que en un manual de traducción alternativo el nombre "Wilt" denote a la sombra de Wilt y el predicado "es alto" a la sombra de las cosas altas. Así, en el primer manual de traducción o teoría, la oración "Wilt es alto" es verdadera si y sólo si Wilt es alto, pero en el segundo, "Wilt es alto" es verdadero si y sólo si la sombra de Wilt es la sombra de algo alto. Las condiciones de verdad son iguales y en este sentido: "one might say that the same fact makes the sentence true in both cases." (Davidson, 1979, p. 230)

${ }^{100}$ Podríamos "without contradiction accept both only if both can be true, and clearly this is not the case." (Davidson, 1979, p. 231)
} 
que permite decidir entre teorías interpretativas es la conducta verbal; no existen otros hechos relevantes sobre los cuales nos apoyemos para elegir un manual de traducción (teoría interpretativa).

Ahora bien, como ya hemos visto, la solución a la IR propuesta por Quine consiste en relativizar la referencia a un lenguaje de fondo o teoría. Davidson, al igual que Field, encuentra esta propuesta fallida bajo el presupuesto general de que la relativización presupone negar la IR misma, la cual se desea conservar. Apoyándose ampliamente en la crítica de Field, Davidson impugna a Quine la incompatibilidad de la OR y la IR. No obstante, no desecha de todo el proyecto quineano (y por eso me parece importante la solución de Davidson, y creo, también le parecería atractiva al mismo Quine): “what I am really objecting to is not any way of relativizing reference, for I shall in the end propose a way." (Davidson, 1979, p. 232) El problema con la relavidad quineana reside en su efecto determinador de la ontología, ${ }^{101}$ consecuencia incompatible con la IR. Más específicamente, el problema reside parcialmente en el cierto grado de arbitrariedad con que se pretende fijar la referencia, pues estando ésta indeterminada el intérprete o traductor se ve en la necesidad de elegir arbitrariamente (según Davidson) una de las diversas permutaciones posibles:

The fixing is only relative to an arbitraty choice. That choice is not dictated by any relevant evidence. Hence the inscrutability. This reply misses the point of the difficulty. The fixing of reference and ontology for the object language has been done on the basis of an arbitrary choice; but the arbitrary choice succeeds in doing this only if the relativized 'refers' of the metalanguage has somehow been nailed down. And this is what we argued cannot be done for any language. (Davidson 1979, p. 232)

\footnotetext{
${ }^{101}$ Respecto a la reinterpretación de una ontología de objetos a sus complementos cósmicos, Quine afirma: "Bodies still continue, under each interpretation, to be distinct from their cosmic complement and from their singletons; they are distinguished in a relativistic way, by their roles relative to one another and to the rest of ontology. Hence my watchword ontological relativity.” (1992a, p. 34) Parece claro que la relativización de la ontología determina en alguna medida la ontología.
} 
El problema reside, pues, en la imposibilidad de llevar a cabo la relativización de la ontología si no se cuenta antes con una referencia determinada. Pero la IR precede a toda relativización. Por tanto, la OR no puede seguirse de la IR.

Ahora bien, aceptemos, por el momento, el paso relativizador quineano. Nos encontramos con un nuevo problema: el regreso al infinito. Este problema ya había sido detectado por el mismo Quine en 1969 (en su exposición más extensa y explicita sobre la relatividad ontológica). La ontología se determina relativizándola a un lenguaje de fondo, y la ontología de este lenguaje se determina en relación a un lenguaje de fondo más amplio... desgraciadamente siempre queda un lenguaje no relativizado y, por consiguiente, la referencia en este lenguaje indeterminada. ${ }^{102}$ En este punto, uno podría pensar que Quine no toma en serio la expresión "referencia determinada", porque es consciente de la imposibilidad de fijar la referencia del todo. Pero Quine tiene una respuesta, a saber: "tomar nuestros enunciados en sentido literal.” Ahora bien, ¿no implica esto aceptar la determinación de la referencia? En otras palabras, quizás la referencia no sufre de una indeterminación paralizadora; algo permanece, lo cual posibilita la comunicación. ${ }^{103}$ Probablemente Quine piensa compatibilisticamente sobre la conjunción entre IR y OR; quizá su compatibilismo es de corte davidsoniano: “In this paper I discuss my difficulties and offer Quine a way out of one of them. Of course, I hope that my way out is what Quine had in mind all along. In that case the exercise will be of no use to him, but will have been to me." (Davidson, 1979, p. 227) Tal vez Quine tiene en mente otra solución, o quizás realmente es presa de una inconsistencia. Según Paul Roth "Quine's claim is that reference lacks determinacy — a fact of the matter — even when spoken of from

\footnotetext{
102 "Quine sees an infinite hierarchy of theories or languages each of which tries vainly to stabilize the reference scheme of the language for which it provides the theory." (Davidson, 1979, p. 232)

103 Según Paul Roth (1986, p. 449) la objeción del regreso al infinito no representa mayor problema: “An infinite regress of coordinate systems is avoided by the fact that one of these "coordinate systems" modes of translating referential terms etc., is just the first language which we learn: our mother tongue". La referencia está pues en algún sentido determinada pero no lo suficiente como para estar "determinada completamente: "Our native tongue does not possess some special determinacy other languages lack." (Roth, 1986, p. 449) Sin embargo, como ya se mencionó, tomar nuestro lenguaje al pie de la letra no resuelve el problema de la IR.
} 
within the framework of an accepted theory." (1986, p. 444) De lo anterior, parece obvio que Quine pretende retener ambas tesis, la IR y la OR

Pero, ¿Realmente Quine no sé percató de las dificultades originadas a partir de esta inconsistencia? Nos quedan dos posibilidades: a) Quine ha albergado en mente alguna forma de compatibilismo todo el tiempo; b) nuestro filósofo no reparó en la patente inconsistencia y sus consecuencias potenciales. A lo largo de estas páginas he tratado de convencer al lector de que la opción adecuada corresponde a (b). No obstante, (a) podría ser una buena respuesta. En este caso, tendríamos que reprocharle a nuestro filósofo el no haber expuesto sus pensamientos de una forma clara. Quizás, él mismo era presa de desconcierto sobre qué forma debería tomar aquella forma de compatibilismo.

Otra crítica desarrollada por Field (cf. Capítulo II), a la OR va dirigida a la analogía quineana entre referencia y la localización de objetos o la velocidad de los mismos. Como ya hemos visto, para Quine, la pregunta por la referencia sólo tiene sentido en relación a un lenguaje de fondo de la misma manera que el preguntar por la localización o la velocidad de un objeto sólo tiene sentido en relación a un sistema coordinado. Davidson tampoco ve ninguna analogía aquí, y si la hay no sirve para sustentar los propósitos de la OR. En el contexto físico, a la pregunta por la ubicación de la casa de Bronk ${ }^{104}$ en el Bronx, corresponde una respuesta definida y completa. Una vez que contamos con el sistema de direcciones del Bronx o un sistema de referencia espacial pertinente, no resulta difícil indicar el lugar exacto donde se encuentra la casa de Bronk. De forma análoga, la pregunta ¿Dónde está el Bronx? Recibe una respuesta clara y completa en relación a un sistema espacial coordinado espacial más amplio. El punto de Davidson establece un hecho fundamental sobre la determinación espacial: siempre es posible determinar la localización o velocidad de cierto objeto en relación a un sistema coordinado pertinente. La relativización de la referencia es otra cosa. La OR, en realidad, es imposible, pues si la referencia en el propio lenguaje no ha sido determinada no podemos comenzar con el proceso relativizador. Además,

${ }^{104}$ Para utilizar el ejemplo de Davidson. 
no hay forma de resolver la indeterminación añadiendo enunciados a nuestros enunciados. Cuanto digamos para intentar determinar el contenido de nuestras propias palabras será en vano puesto que los enunciados agregados están ellos mismos indeterminados. Nos encontramos ante una incoherencia.

\subsubsection{Primacía de las oraciones sobre los términos.}

Como ya hemos visto en el capítulo II, Field propone una forma de determinar la referencia apelando a la teoría causal de la referencia. Davidson analiza esta propuesta a la luz de la IR quineana y llega a la conclusión de que ninguna teoría fisicalista sobre la referencia puede determinar esta última. Esta conclusión gana plausibilidad si consideramos que las propiedades de las palabras: “[...] are abstracted form the semantic features of sentences." (Davidson, 1977, p. 215)

Para Field el rol de la referencia no se agota en su contribución a la condiciones de verdad de las oraciones. Existen conexiones causales entre términos y objetos, las cuales permitirían en última instancia elegir entre uno u otro esquema de referencia aun cuando las condiciones de verdad de las oraciones sean las mismas. Si estas relaciones causales se dan entre palabras y objetos, entonces no deberíamos confirmar nuestras teorías únicamente en base a las relaciones entre oraciones y el mundo. Aún más, la referencia no estaría indeterminada como habría creído Quine. Es cierto que la IR seguiría existiendo para ciertos términos como "masa", pero este tipo de IR deja de ser la IR problemática en el momento en que advertimos que los términos indeterminados refieren determinadamente a por lo menos dos referentes.

A primera vista la tesis referencial-causal de Field parece más apropiada. De hecho, corresponde a una forma naturalista de considerar la cuestión referencial. Sin embargo, ¿la teoría causal de la referencia realmente resuelve el problema de la IR? Davidson opina que no (y Quine seguramente estaría completamente de acuerdo). Veamos sus razones. Según Davidson, Field está sumamente influenciado por las teorías que explican la noción de verdad para una oración mediante la asignación de roles a las 
partes de la oración. Por ello, aboga por una teoría que dé cuenta de las propiedades semánticas de las partes, y particularmente de la referencia. Sin embargo, esta adhesión por parte de Field a este tipo de teorías sobre la verdad de las oraciones le arrastra a una confusión entre explicar la verdad y proveer evidencia de que la teoría es verdadera. Desde un punto de vista quineano-davidsoniano, las teorías se confirman sólo a nivel de las oraciones, aunque pueden explicarse sus propiedades semánticas (como el concepto de verdad) apelando a una estructura oracional interna:

It is the semantic features of sentences (for example truth) that should be viewed as most directly connected with the evidence, while the semantic features of words, however posited, would do their work provided they explained the features of sentences: to take this stance is to assume that truth is easier to connect with non-linguistic evidence than reference. For this I think we can make a good case $[. .$.$] even if words do have, say, causal connections with what they refer to,$ this does not mean that the adequacy of a theory of truth is not to be tested at the sentential level. (Davidson, 1979, p. 236)

Quine no apela a la distinción evidencia-explicación -al menos no directamente-, pero su posición concuerda sin problemas con la de Davidson. Para el primer filósofo, la razón de la referencia, de la segmentación de las oraciones en palabras cuya conexión con objetos se presupone, obedece a nuestra necesidad de aprender el lenguaje teórico (el cual aprendemos de manera composicional). No aprendemos las relaciones inferenciales entre oraciones una por una, más bien debemos reconocemos formas y patrones, $y$ : "this requires that we attribute forms to sentences, that is, see them as made up of constituent parts and patterns that are significant and recur in other sentences." (Hylton, 2004, p. 137)

Davidson es un quineano en este respecto. Si suponemos verdadera la teoría causal de la referencia ¿Cómo sabríamos si es empíricamente y/o naturalisticamente adecuada? Sólo, dice Davidson, si la teoría causal se acopla al comportamiento lingüístico (actual y potencial) de los hablantes. Ahora bien, el comportamiento se conecta directamente con oraciones y no con palabras. Quine expresa esta concepción (donde se muestra conciente de la importancia relativa de expresarse en términos causales) 
en Word and Object: "Instead of speaking merely of stimulations under which the native will assent or dissent to the queried sentence, we speak in a more causal vein of stimulations that will prompt the native to assent or dissent to the queried sentence." (1960, p. 30) Si adoptamos el naturalismo quineano, entonces las relaciones entre estimulaciones y la conducta verbal hacia oraciones precede a las relaciones causales entre términos y objetos: “it is important to think of what prompts the native's assent to 'Gavagai?' as stimulations and not rabbits. Stimulations can remain the same though the rabbit be supplanted by a counterfeit [...] it is stimulations that must be made to match, not animals." (Quine, 1960, p. 31)

La relación entre oraciones y mundo es una condición de posibilidad de la teoría causal. Así: "[...] determining that a causal theory of reference is true for a speaker must depend on evidence drawn from how sentences are viewed or used as much as any other theory of language." (Davidson, 1979, p. 237)

El objetivo principal de un manual de traducción es la comunicación (y explicar la posibilidad de ésta) no la referencia. Esta última noción tiene una función explicativa, como medio para la consecución de una traducción efectiva. (Quine, 1960, p. 70) Esta forma de concebir el asunto concuerda perfectamente con la forma quineana de concebir la ontología:

Reference and ontology recede thus to the status of mere auxiliaries. True sentences, observational and theoretical, are the alpha and omega of the scientific enterprise. They are related by structure, and objects figure as mere nodes of the structure. What particular objects there may be is indifferent to the truth of observation sentences, indifferent to the support they lend to the theoretical sentences, indifferent to the success of the theory in its predictions. (Quine 1993, p. 31)

Sentences, in their truth or falsity, are what run deep; ontology is by the way. (Quine 1977, pp. 164) 
A fin de cuentas, Quine (véase Kemp, 2003, p. 46) y Davidson (1990b) no niegan la existencia de una relación causal entre lenguaje y mundo, pero si alguna importancia conlleva esta relación debe buscársele primeramente en la conexión entre oraciones y el mundo.

\subsubsection{Funciones Proxy y la teoría causal.}

Sin embargo, la objeción más sólida contra la teoría causal proviene del argumento quineano para la IR, a saber: el que utiliza las funciones proxy.

Supongamos una relación causal entre un término y un objeto, y una función proxy. Dada la palabra, "conejo" y su correlato causal un conejo, tendríamos:

- "conejo" se refiere a conejo si y sólo si existe una conexión causal entre la palabra "conejo" y un cierto conejo.

Ahora empleemos la función proxy y reinterpretemos “conejo" por su proxy. El resultado consiste en una nueva teoría empíricamente indistinguible de la primera, con referencia distinta. La relación causal se sigue dando, pero ahora entre el término "conejo" y la nueva referencia (quizás, partes-noseparadas-de-conejo). Gracias a la función proxy, la referencia ha variado, la extensión de las dos teorías no es la misma; aún más, la relación causal también ha variado. De esto se sigue que la relación causal no determina la referencia y que:

No causal theory, nor other 'physicalistic' analysis of reference, will affect our argument for the inscrutability of reference, at least as long as we allow that a satisfactory theory is one that yields an acceptable explanation of verbal behavior and dispositions. For the constraints on the relations between reference and causality (or whatever) can always be equivalently captured by alternative ways of matching up words and objects. The interpreter of the scheme will, as before, be able to tell that the schemer's schemes are different form one another, but he well not be able to pick out a unique correct way of matching the schemer's words 
and objects. It follows that the schemer cannot have used words that determined a unique scheme. Reference remains inscrutable. (Davidson, 1979, p. 237)

El punto de Davidson no radica en condenar como falsa a la teoría causal de la referencia, sino en que de ser verdadera no influye de manera alguna sobre la determinación de la referencia o la verdad de las oraciones. Posteriormente a la introducción de la referencia parcial Field toma cierto grado de consciencia a este respecto, aunque sigue empeñado en la existencia de una relación causal determinada entre palabras y objetos no importa que tan remota se halle:

It might be objected that naturalistic facts can't determine even the partial referents of our concepts, on the grounds that it is somewhat arbitrary which things you count as partial referents of a concept. But this just shows that 'partially refers' (and associated terms like 'determinate' and 'borderline case') themselves refer indeterminately. Higher order indeterminacy is just indeterminacy in our semantic terms. (Field 1998, p. 269-70)

El problema con esta respuesta es que parece entrañar (o ser vulnerable a) un regreso al infinito hacia niveles de indeterminación cada vez más profundos.

La alternativa causal presenta otro problema: a pesar de aceptar la IR (determinación parcial de por lo menos dos referentes). Field termina concediendo la completa determinación de la referencia en un segundo nivel (o tercero, o cuarto...). Pero, como hemos visto, la primacía semántica corresponde a las oraciones. Por tanto, la determinación de la referencia nos está vedada. De igual manera, el argumento de las funciones proxy demuestra la incapacidad de la teoría causal de la referencia para evitar la IR quineana.

\subsection{Relativización reconsiderada: relatividad davidsoniana.}

Davidson nos propone una nueva forma de entender la relatividad. Ésta se caracteriza, en contraposición a la OR quineana, porque no presupone la determinación de la referencia, y, así, evita la inconsistencia en el sistema filosófico quineano. Todo lo que la relatividad davidsoniana implica es que 
el lingüista interpreta al hablante nativo como refiriendo a uno u otro objeto dependiendo del manual de interpretación que esté ocupando. No obstante, la relativización no implica una determinación de la referencia del tipo que Quine tenía en mente.

\subsubsection{Relatividad sin determinación.}

Davidson no desecha toda el proyecto relativizador quineano; al final propone una forma de relativizar la ontología. La relativización propuesta responde a ciertas preguntas, entre ellas: ¿Qué esquema referencial uno usa al traducir o interpretar a alguien? ${ }^{105}$ Por ejemplo, cuando intentamos traducir el nombre "Wilt" -en boca de una persona cuyo lenguaje es distinto al nuestro- como refiriéndose a la sombra de Wilt, uno debe explicar, también, como traducimos el predicado "es alto" de forma adecuada (a forma de compensación) a la interpretación de "Wilt". En este sentido la traducción es relativa a un esquema determinado (un esquema de interpretación o traducción). Sin embargo esta forma de relativizar difiere de la de Quine, pues la primera "may not settle matters of reference, but it does settle how I answer all sorts of questions about what the speaker means or refers to by a word or sentence.” (Davidson, 1979, p. 238)

Quine pretende determinar la referencia mediante una especie de relativización (OR). La elección de cierto esquema de referencia determinaría en última instancia cuales objetos realmente existen. Pero esto es lo que Davidson (y Field) niega desde el principio. La renovada relativización no determina lo que hay; más bien, nos provee de los medios para interpretar las palabras de quien no habla nuestro lenguaje: "All that we can say gets fixed by the relativization is the way we answer questions about reference, not reference itself." (Davidson, 1979, p. 239)

\footnotetext{
${ }^{105}$ Como Quine, Davidson (1973, p.125) no limita la labor interpretativa a la traducción del lenguaje nativo, más bien: “The problem of interpretation is domestic as well as foreign".
} 
Ciertamente, existe un tipo de relativización, pero este se restringe a la atribución de un lenguaje dado a un hablante o comunidad de hablantes en particular. En contraste con la OR quineana, la nueva relatividad no determina la ontología asociada al término "conejo". La ontología de puede consistir en conejos, partes-no-separadas-de-conejo, episodios-de-conejo, etc. Por otro lado, el intérprete si determina, mediante la relativización a un manual o lenguaje, a que se refiere el nativo: a conejos, partesno-separadas-de-conejo, episodios-de-conejo, etc. Por lo tanto, si el lingüista interpreta al nativo conforme al manual $A$, el término "conejo" se refiere a conejos; si se emplea el manual $B$, el término “conejo" se refiere a partes-no-separadas-de-conejo; si utilizamos el manual $C$, el término se referirá a episodios-de-conejo, etc. Tomamos al sujeto como hablando un lenguaje específico según interpretemos sus palabras. Por ejemplo, si interpretamos su palabra "conejo" como refiriéndose a conejos, le estamos atribuyendo un lenguaje; si interpretamos el mismo término como refiriéndose a partes-no-separadas-deconejo, entonces le estamos atribuyendo otro lenguaje.

Davidson (1979, p. 240) rescata la indeterminación quineana también a nivel de significado o IT. El lingüista ${ }^{106}$ goza de toda la libertad que la evidencia le concede para atribuir uno de varios lenguajes posibles al nativo. Sin embargo, como veremos abajo, ahora la indeterminación presupone un lenguaje (sobre todo una teoría del lenguaje desconocido) más incluyente, conformada por significado, creencias, actitudes evaluativas, etc. La interrelación entre estos componentes permite atribuir diferentes lenguajes al nativo si realizamos los ajustes compensatorios necesarios en los elementos mencionados.

\footnotetext{
${ }^{106}$ La interpretación radical davidsoniana se diferencia de la traducción radical quineana primordialmente en que la primera reconoce la naturaleza intencional del lenguaje (contra el conductismo de la segunda) y sitúa los estímulos más allá (en el mundo; en lo intersubjetivamente compartido por la comunidad de hablantes) de la activación neuronal o irritación de los sentidos. (Davidson, 1990b) Quine expone su negativa a adoptar la posición distal davidsonina en 1990, p. 371.
} 


\subsubsection{Relatividad davidsoniana.}

La relativización davidsoniana es mucho más amplia que la quineana, pues el lenguaje o estructura de oraciones forma parte de un sistema más grande que engloba, deseos, creencias, intenciones, etc.; se trata de "our total theory of a person." (Davidson, 1979, p. 240) Todos los factores importan y están interrelacionados. Cuando traducimos el lenguaje de una persona, consideramos sus creencias, intenciones y deseos, los ajustamos y acoplamos a nuestra interpretación de los términos del lenguaje bajo estudio. Nos encontramos con una especie de holismo (semejante al holismo-quineano esbozado en el primer capítulo), donde se considera una gama más amplia de la psicología humana y asuntos relacionados al habla. Así, podemos atribuir diferentes lenguajes a una misma persona o comunidad de personas siempre y cuando hagamos los ajustes pertinentes en las actitudes atribuidas a los hablantes. Los ajustes permiten un espacio de maniobra bastante considerable: las tesis quineanas sobre la indeterminación del significado y la indeterminación de la referencia encuentran en la renovada relatividad un campo fértil donde desarrollarse. Desde el punto de vista de Davidson, (y desde el de Quine también), las cuestiones sobre la verdad y la referencia no dependen sólo de la realidad, de cómo es el mundo. Existe cierto grado de libertad de acción. Cuando se trata del uso de oraciones, sus valores de verdad pueden reinterpretarse de forma que se acoplen a toda la evidencia disponible; lo mismo vale para la referencia:

There are often cases, I believe with Quine, when the totality of relevant evidence in a person's behavior is equally well handled by each of two theories of truth provided we make compensating adjustments in our theory of his beliefs and other attitudes, and yet where on one theory a particular sentence is interpreted in such a way as to make it true, and on the other not. (Davidson, 1979, p. 239)

Aún más, aunque la verdad esté determinada la referencia seguiría estando indeterminada: 
But even if we consider truth invariant, we can suit the evidence by various ways of matching words and objects. (Davidson, 1979, p. 240)

Davidson reformula la IT quineana en una teoría cuyo universo abarca (básicamente) significados, intenciones, creencias y diversas actitudes evaluativas (véase Davidson, 1997). Más aún, la noción de significado está estrechamente ligada a estas otras nociones: "Davidson reconceives meaning, as given by a theory of meaning, as a core concept in a unified theory of an agent's actions and attitudes." (Joseph, 2004, p. 75; veáse también Ellis, 2011; Davidson, 1976; 1974); "In a theory of radical translation (as Quine calls it) there is no completely disentangling questions of what the alien means from questions of what he believes." (Davidson, 1967, p. 27; véase también 1975) Davidson adopta la tesis holista semántica quineana ${ }^{107}$, pero además del significado, toma en cuenta todas las actitudes proposicionales $^{108}$ :

We identify thoughts, distinguish among them, describe them for what they are, only as they can be located within a dense network of related beliefs [...] In order to believe the cat went up the oak tree I must have many true beliefs about cats and oak trees, this cat and this tree, the place, appearance and habits of cats and trees, and so on; but the same holds if I wonder whether the cat went up the oak tree, fear that it did, hope that it did, wish that it had, or intend to make it do so. (Davidson, 1982, pp. 98-9)

There are, as I have argued, no beliefs without many related beliefs, no beliefs without desires, no desires without beliefs, no intentions without both beliefs and desires. (Davidson, 1997, p. 126)

\footnotetext{
${ }^{107}$ Davidson habla, más bien, de holismo de lo mental: "To have the concept of a cat, you must, have the concept of an animal, or at least of a continuing physical object, the concept of an object that moves in certain ways, something that can move freely in its environment, something that has sensations." (1997, p. 124, también 1975) Sin embargo, por cuestiones de espacio, no discutiré los detalles.

108 Véase Harman, 1967, p. 42, para una discusión sobre la postura general de Quine respecto del estatuto de propoposiciones y oraciones (especificamente su rechazo de entidades intensionales).
} 
Así, Davidson rescata la noción de indeterminación en la traducción en un sentido amplio (IT más IR. Véase el capítulo I), en tanto los hechos del mundo y las disposiciones del hablante no determinan el significado y la referencia. Sin embargo, podemos recurrir a un manual de traducción o interpretación y relativo a éste conocer el significado y las creencias del hablante. Podemos también cambiar de manual y atribuir diferentes significados, creencias y referencias (siempre y cuando realicemos los ajustes necesarios $)^{109}$ igualmente adecuados dada la evidencia. Asimismo, los valores de verdad de las oraciones pueden reinterpretarse de forma que se acoplen a toda la evidencia disponible. Así:

Davidson agrees with Quine (roughly speaking) that there can be nothing more to meaning (and the propositional attitudes more generally) than what can be gleaned from observation (propositional attitudes are evidence-dependent in this sense), and that observation will never determine these attitudes uniquely (the attitudes are indeterminate). (Rawling, 2003, p. 92)

Aunque el principio de caridad disminuye la IT y la IR, no la cancela por completo; siempre existe algún grado de indeterminación. La interrelación de todos estos elementos - deseos, creencias, acciones, significados, etc. -, permite aún un amplio margen de maniobra a la hora de formular y/o escoger un manual de traducción relativo al cual damos cuenta de las palabras del hablante: "the evidence on which all these matters depend gives us no way of separating out the contributions of thought, action, desire, and meaning one by one. Total theories are what we must construct, and many theories will do equally well.” (Davidson, 1979, p. 241) Así, Davidson rescata la IR y la OR, y evita la inconsistencia en la filosofía quineana.

\footnotetext{
${ }^{109}$ Creencia y significado se implican mutuamente, de hecho: "Meaning and belief must be accessed simultaneously." (Rawling, 2003, p. 94) Si uno atribuye cierta creencia a un agente $x$, debemos atribuir también un significado a sus palabras. El intérprete trata de equilibrar creencia y significados según el principio de caridad. Esto deja al interprete con cierto grado de libertad sobre como traducir (o interpretar) al hablante, pues podemos atribuir un significado diferente a las oraciones del hablante si modificamos sus creencias y viceversa. Por ejemplo, si el sujeto $x$ dice que la tierra no es redonda, uno puede tomar su exclamación en sentido literal y atribuirle una creencia falsa o bien se puede interpretar su aserción como diciendo: la tierra es casi redonda pero en realidad es un esferoide oblato, entonces uno le atribuye una creencia verdadera. Así, puede mantenerse constante el significado o la creencia pero entonces debemos modificar la creencia o el significado correspondiente.
} 


\section{CONCLUSIÓN}

Toda la discusión se ha centrado en la IR y la controversial solución quinena, a saber: la OR. También se han analizado otro tipo de soluciones, específicamente las de Field y Davidson. Estos últimos han criticado fuertemente la OR quinena pues han mostrado su inconsistencia con la tesis de la IR. La inconsistencia salió a la luz gracias a la obra de Field. Este mismo autor nos proveyó de una nueva manera de darle sentido a la noción de referencia mediante el reconocimiento de relaciones causales entre palabras y objetos. Sin embargo, en la obra de Davidson hemos encontrado, asimismo, buenas razones para considerar irrelevante la teoría causal. Si tomamos en serio las funciones proxy, mantiene Davidson, las relaciones causales sufren del mismo tipo de indeterminación que aquejaba en un principio a la noción de referencia. Así, la conclusión - contra Field- es que ninguna teoría fisicalista de la referencia sirve para refutar la IR.

Davidson, tratando de resolver la presunta paradoja explicitada por Field, propone una nueva forma de relativizar la ontología. Davidson expone los puntos débiles de la teoría quineana y no escatima en reconocer la probabilidad de que Quine mismo ya hubiera vislumbrado una solución similar a la suya. Lo haya o no pensado Quine, Davidson amplía la OR, añade a los factores clave ya existentes otros más: una teoría sobre las creencias, los deseos, y otras actitudes proposicionales. La OR davidsoniana no pretende ofrecer una determinación de la referencia (como la de Quine). Más bien, da cabida a la IR pero al mismo tiempo da sentido al predicado "relativo". Ahora, se relativiza a fin de interpretar a un hablante, a fin de darle sentido a sus palabras, no para fijar la ontología. La referencia sigue estando indeterminada 
y, sin embargo, la relativización nos permite lidiar con la no-determinación completa tanto de la verdad como de la referencia por parte de los hechos relevantes.

Hasta este punto, la propuesta davidsoniana sigue siendo la más plausible, sobre todo si uno simpatiza con el naturalismo quineano, pues Davidson no rechaza los puntos centrales de la filosofía quineana sino que los rescata utilizando los mismos recursos.

Aún queda labor por hacer en el esclarecimiento de las tesis de indeterminación y temas relacionados. Por ejemplo, ¿Cómo se relaciona la IR con la vaguedad? ¿Existe alguna otra forma naturalizada de solventar las dificultades que plantea la IR? ¿La IR implica genuinamente una forma de antirrealismo? ¿La aproximación conductual quineana a las cuestiones de significado y referencia sigue siendo plausible frente a los nuevos estudios y descubrimientos en las ciencias cognitivas?, etc. Mientras tanto hemos hallado una forma en que, para satisfacción de Quine, IR y OR coexisten pacíficamente. 


\section{REFERENCIAS}

Block, Ned., 1998. Holism: Mental and Semantic. In Craig, E, ed. 1998. Routledge Enciclopedya of Philosophy, vol. 6, pp. 488-493.

Bunt, J., 2003. Japanese Grammar and Verbs. New York: Oxford University Press.

Davidson, D., 1967. Radical Interpretation. In: D. Davidson, ed. 1984. Inquiries into Truth and Interpretation. Oxford: Clarendon Press. pp. 17-36.

., 1973. Truth and Meaning. In: D. Davidson, ed. 1984. Inquiries into Truth and Interpretation. Oxford: Clarendon Press. pp. 125-140.

, 1974. Belief and the Basis of Meaning. In: D. Davidson, ed. 1984. Inquiries into Truth and Interpretation. Oxford: Clarendon Press. pp. 141-154.

., 1975. Though and Talk. In: D. Davidson, ed. 1984. Inquiries into Truth and Interpretation. Oxford: Clarendon Press. pp. 155-170.

., 1977. Reality without Reference. In: D. Davidson, ed. 1984. Inquiries into Truth and Interpretation. Oxford: Clarendon Press. pp. 215-226.

., 1979. The Inscrutability of Reference. In: D. Davidson, ed. 1984. Inquiries into Truth and Interpretation. Oxford: Clarendon Press. pp. 227-242.

., 1982. Rational Animals. In D. Davidson, ed. 2001. Subjective, Intersubjective and Objective. Oxford: Oxford University Press, 95-105.

., 1984. Inquiries into Truth and Interpretation. New York: Clarendon Press.

, 1990a. Representation and Interpretation, in M. Said (ed.), Modelling the Mind, Clarendon Press, Oxford, pp. 13-26.

., 1990b. Meaning, Truth and Evidence, in R. B. Barrett and R. F. Gibson (eds), Perspectives on Quine, Blackwell, Oxford, pp. 68-79.

., 1990c. The Structure and Content of Truth, The Journal of Philosophy, 87(6), 279-328.

, 1991. Three Varieties of Knowledge. In D. Davidson, ed. 2001. Subjective, Intersubjective and Objective. Oxford: Oxford University Press. pp. 205-20.

., 1997. The Emergence of Though. In D. Davidson, ed. 2001. Subjective, Intersubjective and Objective. Oxford: Oxford University Press. pp. 123-134.

., 2001a Subjective, Intersubjective and Objective. Oxford: Oxford University Press.

De Rosa, R. and Lepore, E., 2004. Quine's Meaning Holism. In: R. Gibson, ed. 2004. The Cambridge Companion to Quine. Cambridge: Cambridge University Press. pp. 65-90.

Ellis, J., 2011. The Relevance of Radical Interpretation to the Understanding of Mind. In J. Malpas ed. 2011. Dialogues with Davidson Acting, Interpreting, Understanding. Cambridge MA: The MIT Press. Pp. 191217.

Field, H., 1972. Tarski's Theory of Truth. The Journal of Philosophy, 69(13), pp. 347-375. ., 1973. Theory Change and the Indeterminacy of Reference. The Journal of Philosophy, 70(14), On Reference, pp. 462-481.

, 1974. Quine and the Correspondence Theory. The Philosophical Review, 83(2), pp. 200-228.

1975. Conventionalism and Instrumentalism in Semantics. Noûs, 9(4), pp. 375-405.

1998. Some Thoughts on Radical Indeterminacy. The Monist, 81(2), pp. 253-273.

, 2000. Indeterminacy, Degree of Belief, and Excluded Middle. Noûs, Vol. 34(1), pp. 1-30.

, 2001. Truth and the Absence of Fact. Oxford University Press, Oxford

Fodor, J. and Lepore, E. 1992. Holism: A Shopper's Guide. Cambridge USA: Blackwell. 
Fogelin, R., 2004. Aspects of Quine's Naturalized Epistemology. In: R. Gibson, ed. 2004. The Cambridge Companion to Quine. Cambridge: Cambridge University Press. pp. 19-46.

Føllesdal, D., ed., 2000-2001. Philosophy of Quine. New York: Garland.

Føllesdal, D. and Quine, D. B., eds., 2008. Confessions of a Confirmed Extensionalist, and Other Essays. Cambridge MA: Harvard University Press.

Friedman, M., 1975. Physicalism and the Indeterminancy of Translation. Noûs 9, pp. 353-373.

Gaudet, E., 2006. Quine on Meaning. London: Continuum.

Gibson Jr, Roger F. 1982. The Philosophy of W. V. Quine. Tampa FL: University of South Florida Press. , 1998a. Translation, Physics, and Facts of the Matter. In E. Hahn and P. A. Schilpp eds. 1998. The Philosophy of W. V. Quine. $2^{\text {nd }}$ ed. Peru IL: Open Court. pp. 139-154.

., 1998b. Quine's Philosophy: A Brief Sketch. In E. Hahn and P. A. Schilpp eds. 1998. The Philosophy of W. V. Quine. $2^{\text {nd }}$ ed. Peru IL: Open Court. pp. 667-83. , (ed). 2004. The Cambridge Companion to Quine. Cambridge: Cambridge University Press.

Glock, Hans-Johann., 2003. Quine and Davidson on Language, Thought and Reality. Cambridge: Cambridge University Press.

Greenlee, D., Relativity without Inscrutability. Philosophy and Phenomenological Research, 33(4), pp. 574578.

Hahn, E. and Schilpp, P. A., 1998. The Philosophy of W. V. Quine. $2^{\text {nd }}$ ed. Peru IL: Open Court.

Harman, G. 1967. Quine on Meaning and Existence, I, Review of Metaphysics, 31, pp. 124-51.

Hylton, P., 2002. Analyticity and Holism in Quine's Thought. The Harvard Review of Philosophy, 10, pp, 1126.

2004. Quine on Reference and Ontology. In: R. Gibson, ed. 2004. The Cambridge Companion to Quine. Cambridge: Cambridge University Press. pp. 115-30.

Hylton, P., 2007. Quine. New York: Routledge.

John, W.T. and Fogelin, J. R., 1996. A History of Western Philosophy: The Twenty Century to Quine and Derrida, Volume V.: Harcourt Brace College Publishers.

Kirk, R., 2004. Indeterminacy of Translation: R. Gibson, ed. 2004. The Cambridge Companion to Quine. Cambridge: Cambridge University Press. pp. 151-180.

Kuhn, T. S. 1970. The Structure of Scientific Revolutions, 2nd edn. Chicago, IL: University of Chicago Press. Malpas, J. ed., 2011. Dialogues with Davidson: Acting, Interpreting, Understanding. Cambridge: MIT Press.

Nimtz, C., 2005. Reassesing Referential Indeterminacy. Erkenntnis (1975), 62(1,), pp. 1-28.

Quine, W. V. O., $19532^{\text {nd }}$ edn, 1961. From a Logical Point of View. New York: Harper Torchbooks. , 1954. Carnap and Logical Truth. In The Ways of Paradox pp. 107-132.

., 1957. The scope and language of science, British Journal of Philosophy of Science. 8, pp. 1-17.

., 1958. Speaking of objects. Proceedings and Addresses of the American Philosophical Association, 31, pp. 5-22.

, 1960. Word and Object. Cambridge MA: MIT Press.

., 1964. Ontological Reduction and the World of Numbers. In The Ways of Paradox and other Essays.

New York: Random House, pp. 199-207.

., 1966. The Ways of Paradox and other Essays. New York: Random House.

, 1969. Ontological Relativity and Other Essays. New York: Columbia University Press.

, 1969a. Ontological Relativity. In: Ontological Relativity and Other Essays. New York: Columbia University Press, pp. 26-68.

., 1969b. Epistemology Naturalized, In: Ontological Relativity and Other Essays. New York: Columbia University Press, 1969, pp. 69-90.

, 1970. On the Reasons for the Indeterminacy of Translation, Journal of Philosophy 67, pp. 178-83.

, 1974. Roots of Reference. La Salle IL: Open Court. 
., 1975. Mind and Verbal Dispositions. In: D. Føllesdal and D. B. Quine, eds. 2008. Confessions of a Confirmed Extensionalist and Other Essays. Cambridge MA: Harvard University Press. pp. 244-256.

, 1976 The ways of Paradox and other essays. Cambridge: Harvard University Press.

., 1976b. Worlds away. Journal of Philosophy, 73. Reprinted in Quine, Theories and Things (Harvard University Press, Cambridge MA and London, 1981) pp.124-128.

, 1977. Facts of the matter. In: D. Føllesdal and D. B. Quine, eds. 2008. Confessions of a Confirmed Extensionalist and Other Essays. Cambridge MA: Harvard University Press. pp. 271-286.

., 1981a. Theories and things. Cambridge MA: Harvard University Press.

, 1981b. Empirical Content, in Theories and Things. Cambridge MA: Harvard University Press, pp. 2430.

., 1983. Ontology and ideology Revisited, In: D. Føllesdal and D. B. Quine, eds. 2008. Confessions of a Confirmed Extensionalist and Other Essays. Cambridge MA: Harvard University Press. pp. 315-318.

., 1986a. Reply to Paul A. Roth. In E. Hahn and P. A. Schilpp eds. 1998. The Philosophy of W. V. Quine. $2^{\text {nd }}$ ed. Peru IL: Open Court. pp. 459-461.

, 1986b. Reply to Vuillemin. In E. Hahn and P. A. Schilpp eds. 1998. The Philosophy of W. V. Quine. $2^{\text {nd }}$ ed. Peru IL: Open Court. pp. 619-622.

, 1986c. Reply to Harold N. Lee. In E. Hahn and P. A. Schilpp eds. 1998. The Philosophy of W. V. Quine. $2^{\text {nd }}$ ed. Peru IL: Open Court. pp. 315-318.

, 1986d. Reply to Hilary Putnam. In E. Hahn and P. A. Schilpp eds. 1998. The Philosophy of W. V. Quine. $2^{\text {nd }}$ ed. Peru IL: Open Court. pp. 427-431.

., 1987. Indeterminacy of Translation Again. The Journal of Philosophy 84, no. 1, pp. 5-10.

., 1990. Three Indeterminacies. In: D. Føllesdal and D. B. Quine, eds. 2008. Confessions of a Confirmed Extensionalist and Other Essays. Cambridge MA: Harvard University Press. pp. 368-386.

, 1992a. Pursuit of Truth. Revised edition. Cambridge, Mass.: Harvard University Press.

, 1992b. Structure and Nature. In: D. Føllesdal and D. B. Quine, eds. 2008. Confessions of a Confirmed Extensionalist and Other Essays. Cambridge MA: Harvard University Press. pp. 401-406.

, 1993. "In Praise of Observation Sentences', Journal of Philosophy 90, no. 3, pp.107-16.

1994a Indeterminacy without tears. In: D. Føllesdal and D. B. Quine, eds. 2008. Confessions of a Confirmed Extensionalist and Other Essays. Cambridge MA: Harvard University Press. pp. 447-448.

., 1994b Assuming Objects. In: D. Føllesdal and D. B. Quine, eds. 2008. Confessions of a Confirmed Extensionalist and Other Essays. Cambridge MA: Harvard University Press. pp. 447-448.

., 1995a. Naturalism; Or, Living within One's Means. In: D. Føllesdal and D. B. Quine, eds. 2008. Confessions of a Confirmed Extensionalist and Other Essays. Cambridge MA: Harvard University Press. pp. 461-472.

., 1995b. From Stimulus to Science. Cambridge, Mass.: Harvard University Press. Rawling, P., 2003. Radical Interpretation. In Donald Davidson, ed. L. Kirk, pp. 85-112.

Putnam, H., 1962. The Analytic and the Synthetic. In Putnam, H. 1975. Mind Language and Reality. Cambridge: Cambridge University Press. pp. 33-69.

Putnam, H., 1975. The Refutation of Conventionalism. In Putnam, H. 1975. Mind Language and Reality. Cambridge: Cambridge University Press. pp. 153-191.

Reynolds, S., 1994. Proxy Functions and Inscrutability of Reference. Analysis, 54(4), pp. 228-235.

Roth, P., 1986. Semantics without Foundations. In The Philosophy of W. V. Quine, ed. L. E. Hahn and P. Schilpp, pp. 432-58.

Salomon, M., 1990. Extensionality, Underdetermination and Indeterminacy. Erkenntnis (1975), 33(2), pp. 211221.

Vuillemin, J., 1986. On Duhem's and Quine's Theses. In E. Hahn and P. A. Schilpp eds. 1998. The Philosophy of W. V. Quine. $2^{\text {nd }}$ ed. Peru IL: Open Court. pp. 595-618. 